\title{
The safety of masonry buttresses
}

\section{S. Huerta}

The vault is the main element in most historical buildings. Masonry vaults exert an inclined thrust that must be resisted by a substantial mass of masonry: the buttress. The buttress system assures the safety of the whole construction. Most traditional structural design rules addressed the problem of buttress design. Today, an architect or engineer assessing the structural safety of a historical construction needs to estimate the safety of the buttress system with accuracy. This is not an easy matter. Among other possible failures, a buttress may fracture under certain conditions with a substantial loss of stability, it may show a certain leaning or it may be separated from the wall. Furthermore, buttress systems are complex structures - a combination of walls and counterforts, flying buttresses, etc. - made of different types of masonry, and their assessment cannot be handled in an abstract way. This paper outlines the development of buttress design since around 1700 to explain the main approaches used and to provide a historical context. The paper then goes on to summarise the state-of-the-art in modern masonry buttress analysis and to discuss estimations of safety.

\section{INTRODUCTION}

The vault was the main element of monumental architecture for around two millennia until around 1900. Masonry vaults and arches exert, inexorably, an inclined thrust that must be resisted by a substantial mass of masonry or buttress. The buttress system thus assures the safety of the construction; a vault may collapse without serious consequences for the whole building. However, because failure of the buttress system always leads to catastrophic collapse, the safety of vaulted masonry buildings lies in the buttresses. An understanding of this problem may involve an architectural or construction historian trying to understand the structural 'logic' of some buttress forms, and an assessment of the structural safety of a historical construction requires an accurate estimation of the safety of the buttress system.

However, this is a neglected topic. Antiquarians and then medieval archaeologists and architectural historians focused their attention on vaults. For historical engineers and architects, the problem was to evaluate the vault thrust and the theory of masonry arches and domes developed during the eighteenth and nineteenth centuries tackled almost exclusively this problem.
The vault thrust, used to check the stability of a buttress, was considered an exercise of simple statics. However, modern limit analysis allows a more comprehensive analysis of the theory of masonry structures and sheds new light on the study of the safety of vault-buttress systems.

The aim of this work is to draw attention to the buttress, its design and safety, the logic (or lack of logic) of some forms and the possible approaches to its understanding. The paper is addressed to both historians and practitioners, and to anyone interested in reaching a deeper understanding of masonry architecture. The approach is historical and begins by offering an outline of the development of buttress design in order to single out the main issues regarding buttresses and the way they have been resolved in different epochs. Modern architectural historians and architects or engineers working in restoration need an understanding of these problems: first, to complete the historical overview and, second, to gain knowledge about a monument without which any intervention would be deemed to be arbitrary.

\section{TRADITIONAL BUTTRESS DESIGN}

old master builders were well aware of the importance of the buttress system. Before the science of statics was sufficiently developed (say, at the end of the seventeenth century) the only possible approach was the use of empirical structural rules. The approach was not entirely unscientific as each building that stood safely for many years was a successful experiment. The rules codified the sizes of the main structural elements, the depths of buttresses, the thicknesses of arches or ribs, the thickness of walls, etc. Most of the rules that have survived refer to buttress design, and this indicates the importance assigned by the master builders to the crucial problem of deciding the form and size of the buttress for a certain vault or vault system.

The rules were specific to each structural type: rules for designing the buttresses of light Gothic vaults could not be applied to the heavy Renaissance or Baroque barrel vaults of later centuries. This matter has been studied in detail elsewhere (Huerta, 2004). To understand the nature of the design rules, two rules, one Gothic and other stemming from the Renaissance, are now considered.

\section{I. A Gothic design rule}

Gothic design rules were of two types: geometrical and arithmetical. In both cases, the objective was to decide the depth 
of the buttress as a fraction of the span. In late Gothic German manuals of the early fifteenth century, simple fractions are used to decide the main elements (walls, buttresses and rib vaults) and geometrical procedures are then used to define the forms (imposts, mouldings, etc.). In Germany, France and Spain there is indirect documentary evidence of the use of several geometrical rules. These rules survived in the late Renaissance and Baroque stonecutting manuals that followed the tradition of the medieval stonemasons.

The geometrical rule most cited is represented in Figure 1(a). It appeared first in the lost manual of Baccojani, Germany, c. 1550 (Müller, 1990), in the manuscript of Martinez de Aranda, Spain (c. 1590) and was published for the first time in France in the treatise by Derand (1643) (it is usually incorrectly attributed to Blondel who also published it in 1675). It was then published in many stonecutting and architectural manuals until the twentieth century (see, for example, Cassinello 1964). The rule addresses the problem of designing the buttress of a Gothic cross-vault. The profile (elevation) of the transverse arch is used to generate the form and size of the vault (spatial). However, it is remarkable that the height of the buttress is not considered. After the seventeenth century, this rule was misinterpreted as a rule to obtain the dimensions of the buttress for an arch or barrel vault whose intrados was the arc of a circle, but Derand is explicit about its Gothic origin and, besides, the proportions of the

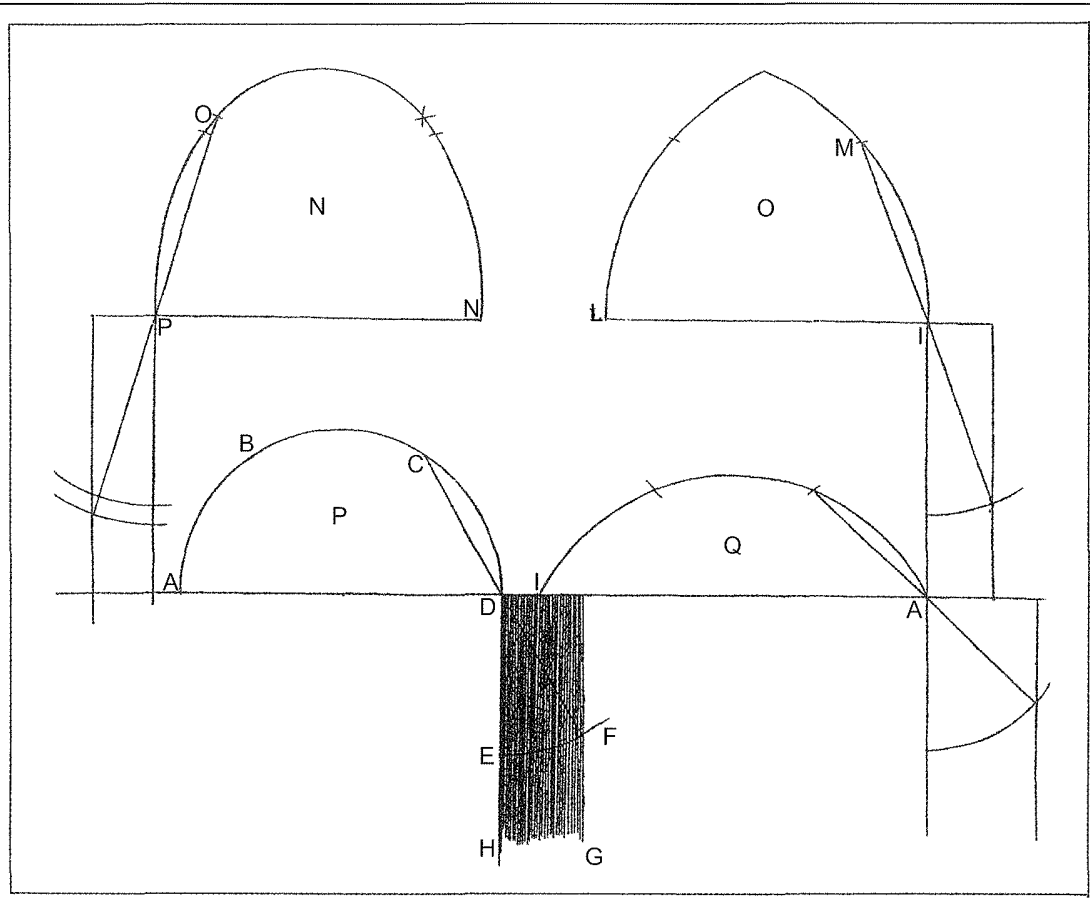

(a)
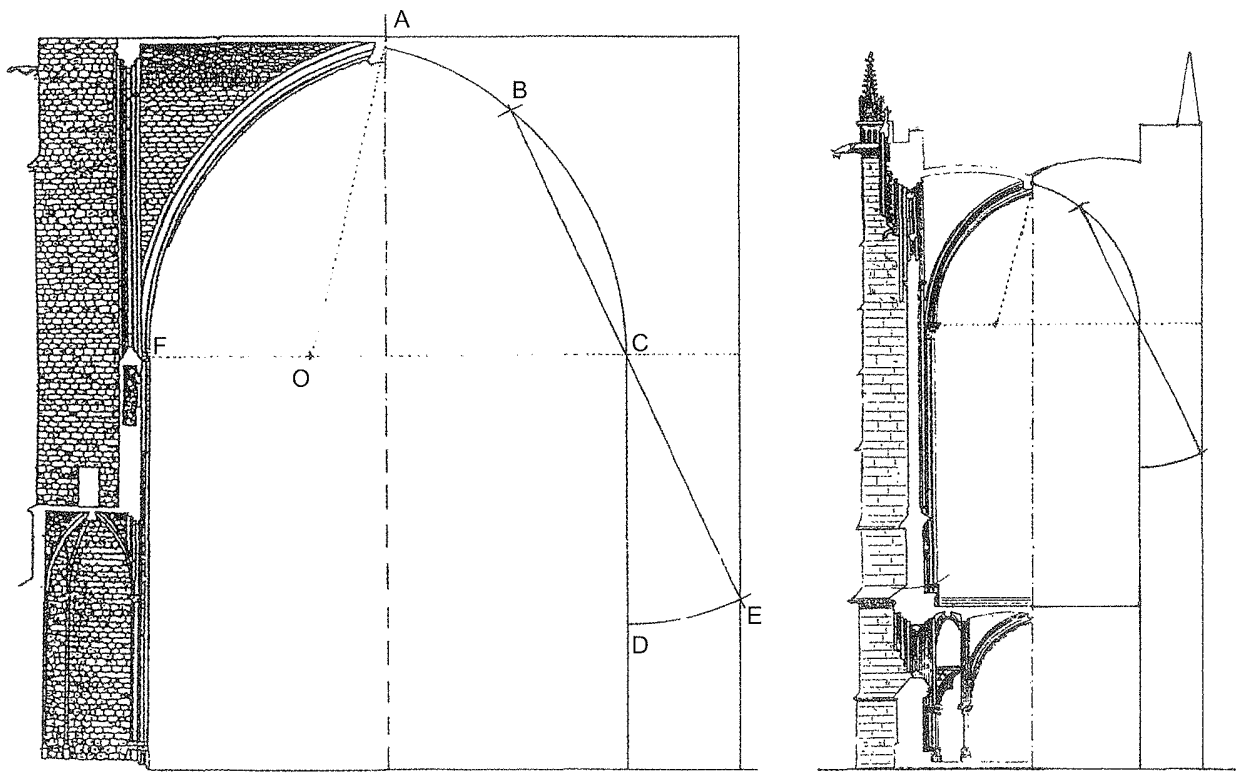

0

$10 \mathrm{~m}$

(b)

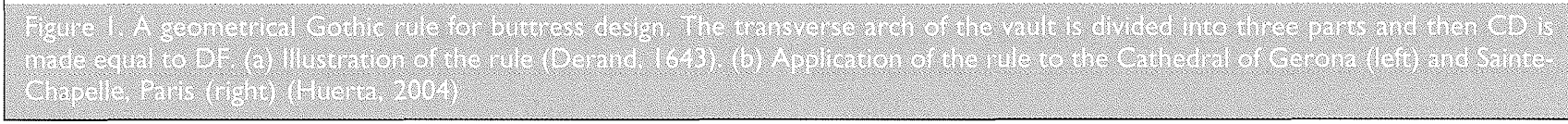




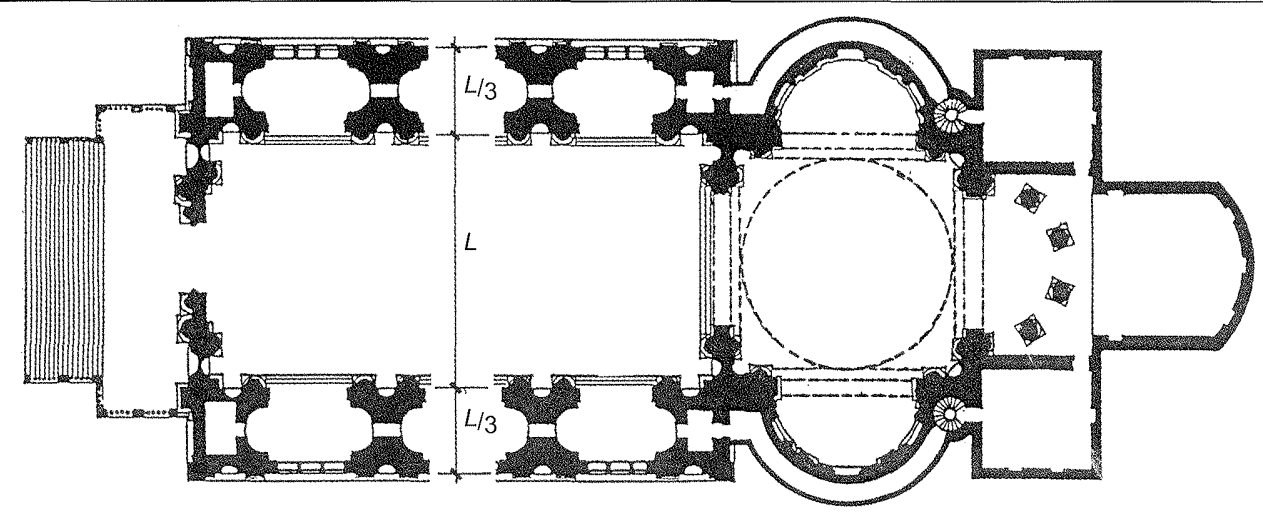

$\stackrel{2+1}{0}$

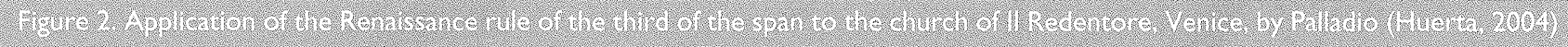

buttresses obtained by the rule are Gothic. Of course, the rule was only a rough guide to the designer to be interpreted only by a master, not to be applied blindly.

\subsection{A Renaissance rule}

Renaissance vaults were usually barrel vaults (sometimes with lunettes). The outward thrust of a barrel vault is much greater than a Gothic vault (typically, its weight might be twice that of a Gothic vault of the same plan). Gothic rules were useless and new design rules were developed, based mainly on observations of Roman ruins and also, perhaps, on inspection of Romanesque churches. As the profile of the vault was always semicircular it was not necessary to consider the form of the vault; a simple fraction of the span was used. The rule stated that the buttress should have a depth between one-third and one-half of the span, as is cited in many architectural manuals (Figure 2). Again, the designer would decide in each case what the precise dimensions should be.

The Spanish architect Fray Lorenzo de San Nicolás presented in his treatise of 1639 a detailed account of the application of the rule (San Nicolás, 1639). He considered three types of vault made of stone, brick with radial joints (half brick thickness, $\approx 150 \mathrm{~mm}$ ) and timbrel vaults made by setting two shells of flat bricks, breaking the joints (typical thickness $100 \mathrm{~mm}$ ). He also considered two types of buttresses - a continuous wall and a wall reinforced with counterforts. His exposition is so systematic that it can be summarised in tabular form (Table 1).

Table 1 shows that, in common with Italian Renaissance design rules, the buttress (wall plus counterfort) should have a depth of at least one-third of the span. The Gothic rule gave a depth/span ratio of 1/4 (for a semicircular transverse arch) or less. This discrepancy is enormous, as it should be considering the difference between both structural types. Of course, the transition between the two types led to some structural disasters. The Renaissance mason, educated in the medieval tradition, would have considered the stereotomy of the 'modern' Renaissance vaults trivial, but would not have known how to determine the precise size of the buttress. In Spain, where Gothic architecture continued to dominate until the eighteenth century, there is documentary evidence of this problem. The architect García Berruguilla (1747) made a comparison of the two rules and remarked that many ruins and disasters stemmed from this discrepancy (Figure 3).

Evidence of the same type of problem came to light in a small Spanish church. Construction of the church began with a Gothic presbytery in around 1650 and was finished in 1699 with a nave covered by a barrel vault (Figure 4(c)). The ignorant master builder used the same buttress to the 'modern' nave (a) with the result that can be seen in (b). The nave had to be assured by a scaffold and additional larger buttresses had to be added to the already greatly distorted vault in around 1700 (Huerta and López-Manzanares, 1997).

\section{SCIENTIFIC BUTTRESS DESIGN}

At the end of the seventeenth century, the science of statics was sufficiently well developed to attempt scientific design of vaults and buttresses. The matter of vault analysis and design has been the subject of numerous publications (an excellent outline is provided by Heyman (1972)). This paper concentrates on the hitherto neglected matter of buttress design and makes reference to vault theories only when necessary.

\begin{tabular}{|c|c|c|c|}
\hline & \multicolumn{3}{|c|}{ Type of buttress } \\
\hline & \multirow[b]{2}{*}{ Wall (uniform section) } & \multicolumn{2}{|c|}{ Wall with counterforts } \\
\hline & & Wall thickness & Wall plus counterfort \\
\hline Stone vault & $1 / 3$ & $1 / 6$ & $\geqslant 1 / 3$ \\
\hline Brick vault, radial joints & $1 / 4$ & $1 / 7$ & $1 / 3$ \\
\hline Brick, timbrel vault & $1 / 5$ & $1 / 8$ & $1 / 4$ \\
\hline
\end{tabular}




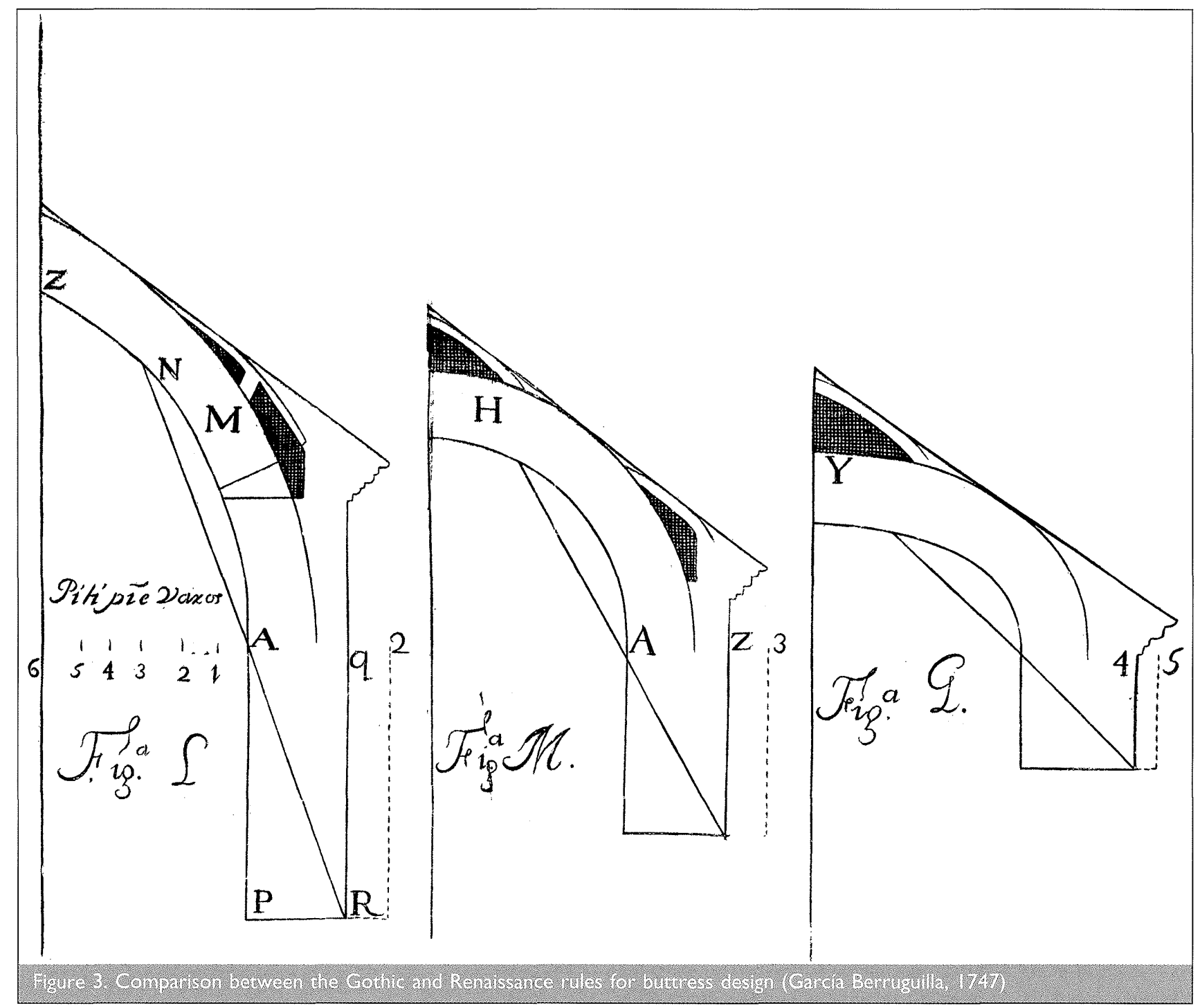

\section{I. The French school}

Philippe de La Hire was the first to attempt buttress design using statical calculations (La Hire, 1712) (Figure 5(a)). To do this he needed to estimate the vault thrust, but his objective was to obtain the depth of the buttress. La Hire assumed that the vault breaks at a certain point (le joint de rupture) where the thrust of the upper part of the vault acts at an inclined angle, approximately tangential to the curve of intrados (Figure 5).

La Hire did not fix the position of the joint of rupture nor, explicitly, the direction of the force. This made the procedure inadequate for practical use, implying some trials to find the worst position. It was Bélidor (1729) who transformed La Hire's idea into an engineering design procedure. Bélidor located the joint of rupture on the intrados equidistant from the impost and the crown; the thrust acts through the centre of the joint and is normal to the plane of joint. In this way, calculation of the arch thrust can be made using a parallelogram of forces (Figure 6(a)).

Bélidor was aware of the usefulness of his method and applied it to many practical situations, even in complex buildings (Figure 6(b)). Of course, the buttress design for a given vault involved the solution of a second-order equation, and Bélidor gave the mathematical solution for many cases. As always this occurs when centres of gravity are involved, the algebraic expressions were somewhat frightening, but to any French engineer this was not a problem (this was not, however, the case for normal architects and master builders who continued applying empirical rules).

La Hire and Bélidor considered the buttress as solid, as a monolith. This may seem surprising since they knew that buttresses were built using discrete stones, but the study of general equilibrium was basically correct. They considered equilibrium at the boundary of the buttress, with the overturning moment of the vault thrust balanced by the moment due to the weight of the buttress. The buttress so obtained was, then, in perfectly balanced equilibrium with the vault and was, therefore, critical and unsafe. Bélidor ensured that the results of his design calculations would be safe by recommending that the buttresses be built a few inches deeper. The fact is that the results based on equilibrium calculations using statics agreed well with the expected results derived using traditional design rules and the observation of existing constructions. We now know that this is because the vault thrust calculated was not the actual thrust in the collapse situation, but much more unfavourable (mainly because of the inclination): the 'wrong' thrust incorporated a margin of safety. Bélidor did not know this, but he knew that the method gave good practical results and he did not enquire further into the problem of safety. Bélidor also studied the case of compound buttresses: a wall 


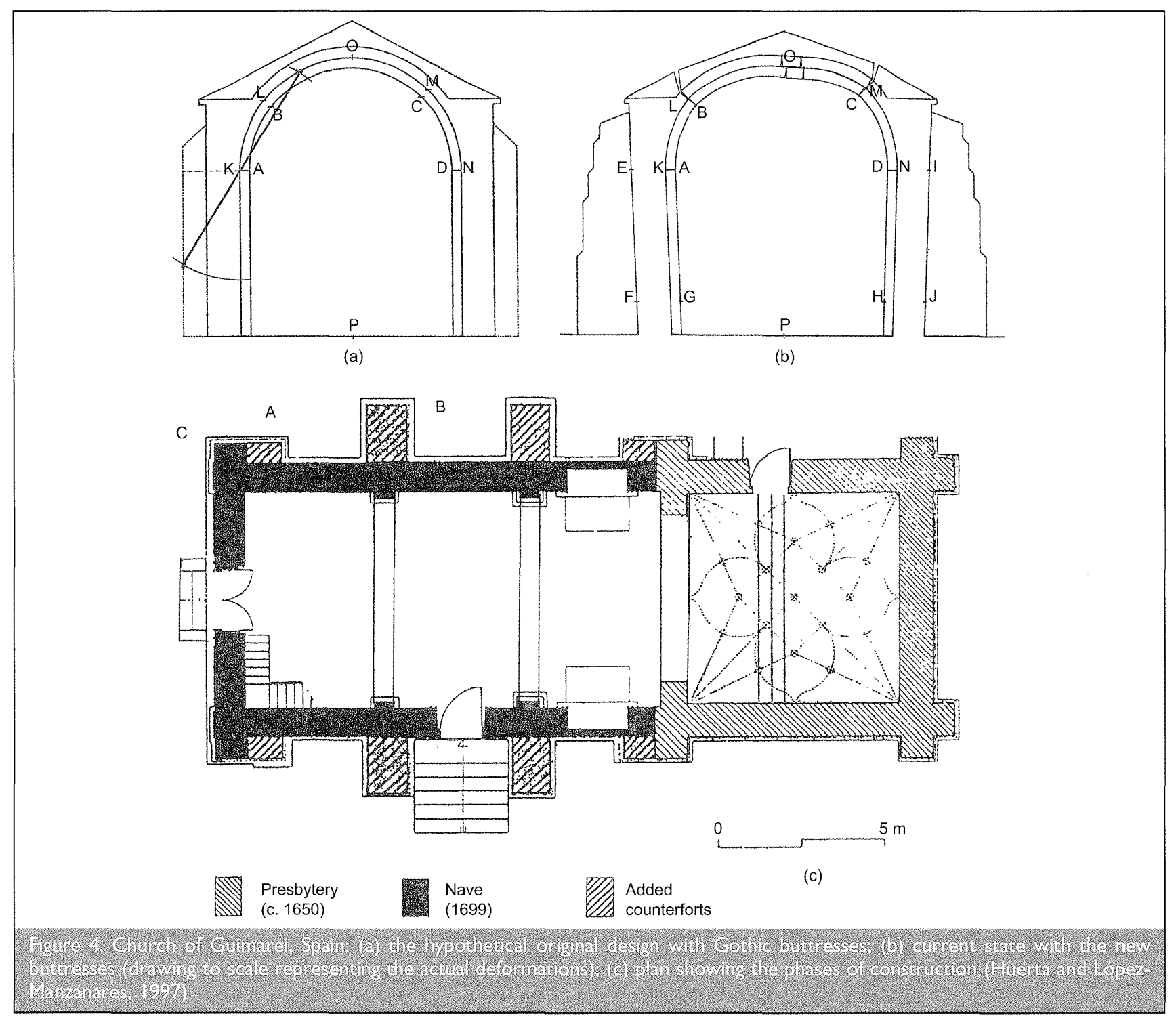

reinforced with counterforts. He continued to treat the wallcounterfort system as a monolith, taking moments with respect to the external border of the counterfort. This was too optimistic, but again Bélidor considered that his calculations gave reasonable and reliable results.
It was French engineer Audoy who was the first to design buttresses using the correct vault thrust (Audoy, 1820). He rediscovered Coulomb's theory of 1773 , which had remained in oblivion for 50 years, and applied it to the calculation of vault thrusts. In the second part of his Mémoire, he addressed
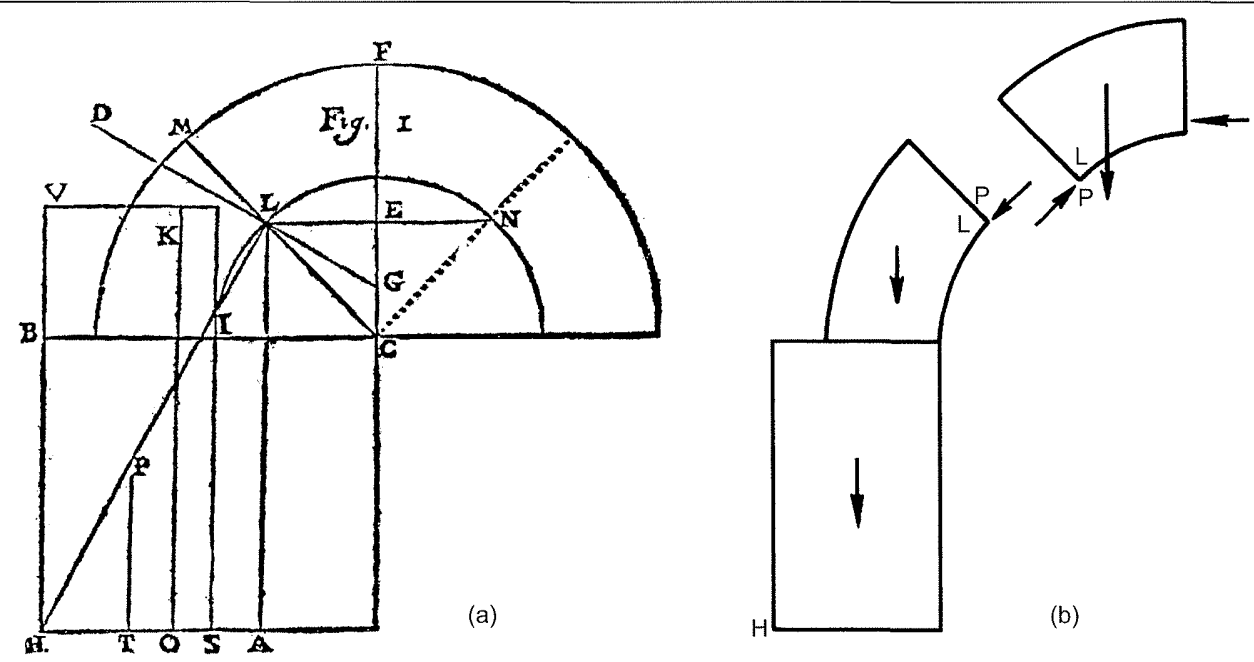


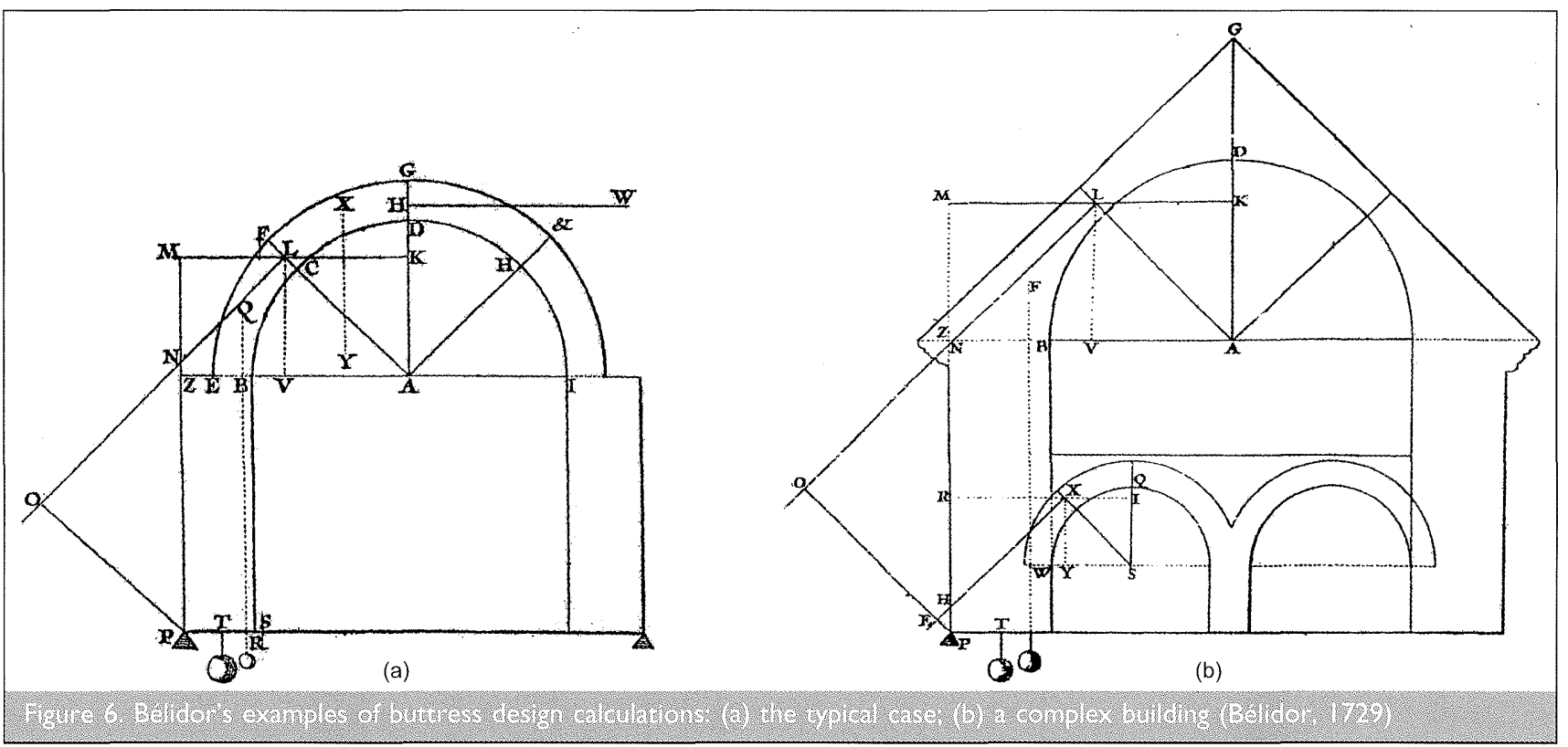

the matter of buttress design. The depths obtained were this time clearly critical (Figure 7) and Audoy was compelled to study the problem of safety. He considered that one way to attack the problem was to multiply the vault thrust (the horizontal thrust at the crown) by a factor. But, how could this factor be determined? He knew that the factor of safety should take into account many different aspects that would be almost impossible to express in mathematical terms. He then decided to be pragmatic: the incorrect theory of La Hire/ Bélidor had been in use for a century, giving good practical results. The factor should be chosen such that the buttress depth would be the same as that obtained using La Hire's method. He used an incorrect theory to calibrate the results of a correct theory - a true engineering approach. In this way he arrived at a numerical value for the factor of safety of 1.9. The procedure was to multiply the vault thrust by this factor and to use the higher thrust to determine the size of the buttress. This buttress would then be safe for the working value of the imposed loads.

This was the French approach to buttress design during the whole of the nineteenth century: the overturning moments, multiplied by a factor, the coefficient de stabilité, were made equal to the stabilising moment produced by the weight of the whole buttress. Again, the consideration of the buttress as a monolith is implicit.

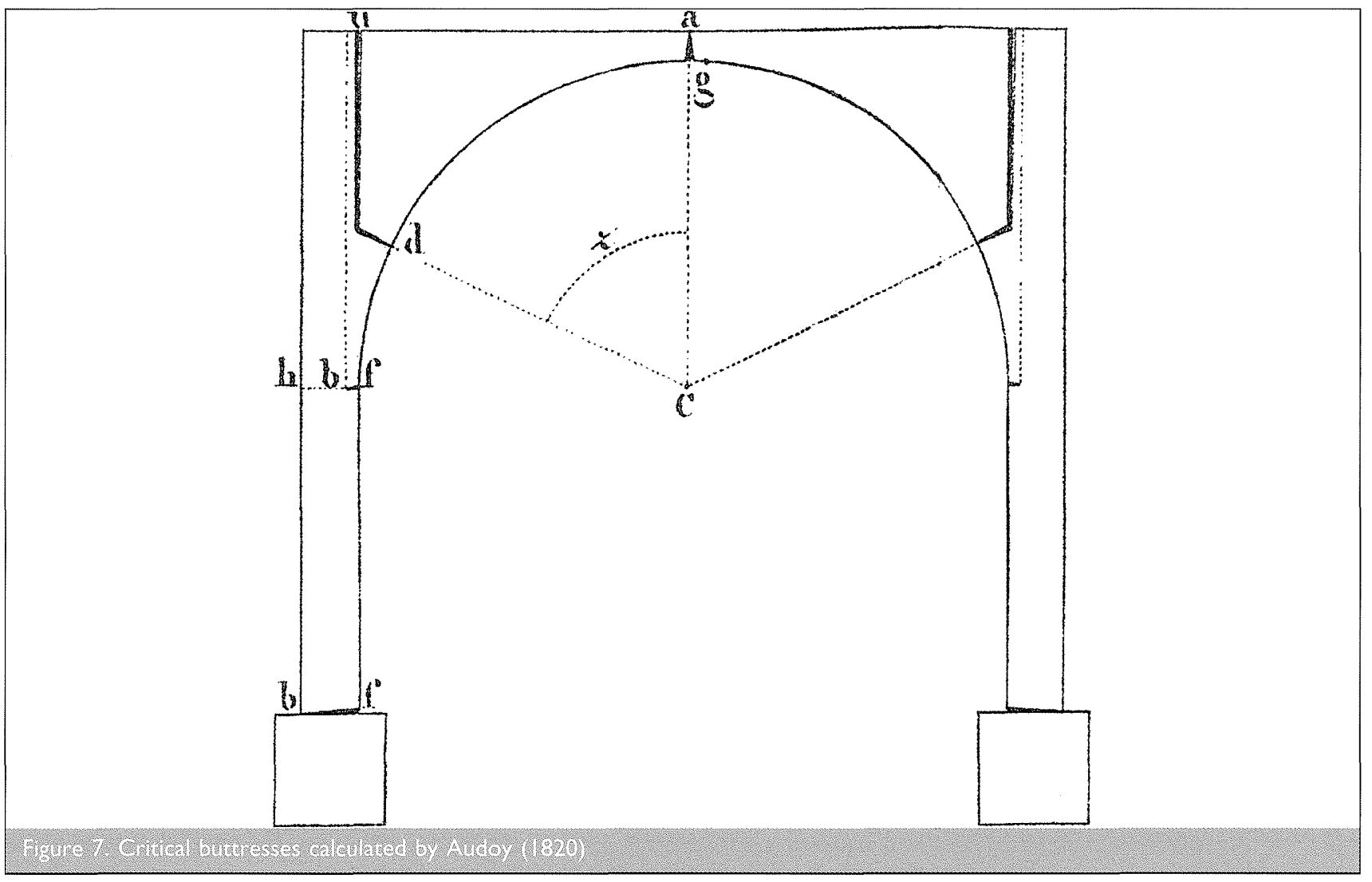


Audoy also considered the compound buttress, and was critical of Bélidor's monolithic assumption. It was unrealistic to assume that the whole weight could be mobilised around the border of the counterfort. He proposed considering the counterfort plus the adjacent wall rotating about the border of the counterfort, and the wall between them rotating about the border of the wall. This would lead to a much thicker buttress system. In general, this part of Audoy's Mémoire was ignored by subsequent French engineers who persisted - all through the nineteenth century in considering the compound as a monolith.

\subsection{The English school}

The French theory considered the arch in a collapse state imaginary in the eyes of La Hire and Bélidor, real after Coulomb and Audoy - and then multiplied the calculated horizontal thrust by a factor of safety to design the buttress. What happened inside the masonry of both the vault and the buttresses (the internal forces) was not considered. English analysis of arches and vaults began with Robert Hooke who, in 1675, made the crucial statement 'as hangs the flexible line, so but inverted will stand the rigid arch'. This was Hooke's solution to the problem of finding the 'true ... form of all manner of arches for building, with the true butmen necessary to each of them', which he included as an anagram, among others, in a postscript to his Description of Helioscopes (Hooke, 1676). There was no explanation, but there is indirect evidence that Hooke considered that the inverted arch could be prolonged inside the abutment, as is shown in one of the preliminary designs made in collaboration with Christopher Wren for the dome of St. Paul's Cathedral (Heyman, 2003; Huerta, 2006).

Hooke's assertion was completed by Gregory a few years later in 1697 '... none but the catenaria is the figure of a true legitimate arch ... and when an arch of any other figure is supported, it is because in its thickness some catenaria is included' (Heyman, 1998a). This is a very powerful statement. However, it was ignored and English engineers and mathematicians dedicated all their efforts to calculating mathematically the form of the "curve of equilibrium', which had to coincide with the intrados (or centreline) of the arch. Of course, the pull of the chain would be the thrust of the arch and, in theory, by the end of the eighteenth century English engineers were in a good position to estimate the correct size of buttresses. In fact, nothing of the sort happened. It is fascinating to see how, for example, Hutton, after having struggled with the complicated mathematics of different curves of equilibrium, was unable to give a reasonable estimate of the buttress size for the simplest case of a bridge and had to revert to a modified version of Bélidor's approach (Hutton, 1812).

It was not until Thomas Young (1817) freed the 'curve of equilibrium' from the straitjacket of having to follow the shape of the intrados that an advance was possible. Young defined the concept of 'line of thrust' as that which '... represents, for every part of a system of bodies supporting each other, the general direction of their mutual pressure'. Any deviation from the intrados (or centreline) of the arch was made possible by the effect of friction, as Young explicitly stated. This crucial contribution by Young was ignored by his contemporaries and remained so until recently (Huerta, 2005).

Henry Moseley (1835) is usually credited with inventing the concept of line of thrust and, indeed, he also presented a complete mathematical theory of arches and buttresses. He first considered the problem of the buttress, in his article of 1838 in a highly abstract way. However, in Mechanical Principles of Engineering and Architecture (Moseley, 1843) he paid great attention to the problems of buttress design with a view to solving practical design problems and studied in detail the transmission of forces inside the masonry itself (Figure 8(a)). In doing so, he improved on the French approach, which only guaranteed the stability of the buttress with respect to its base and ignored the possibility of failure at any other joint in the arch (which can, indeed, be the case in a buttress of varying section).

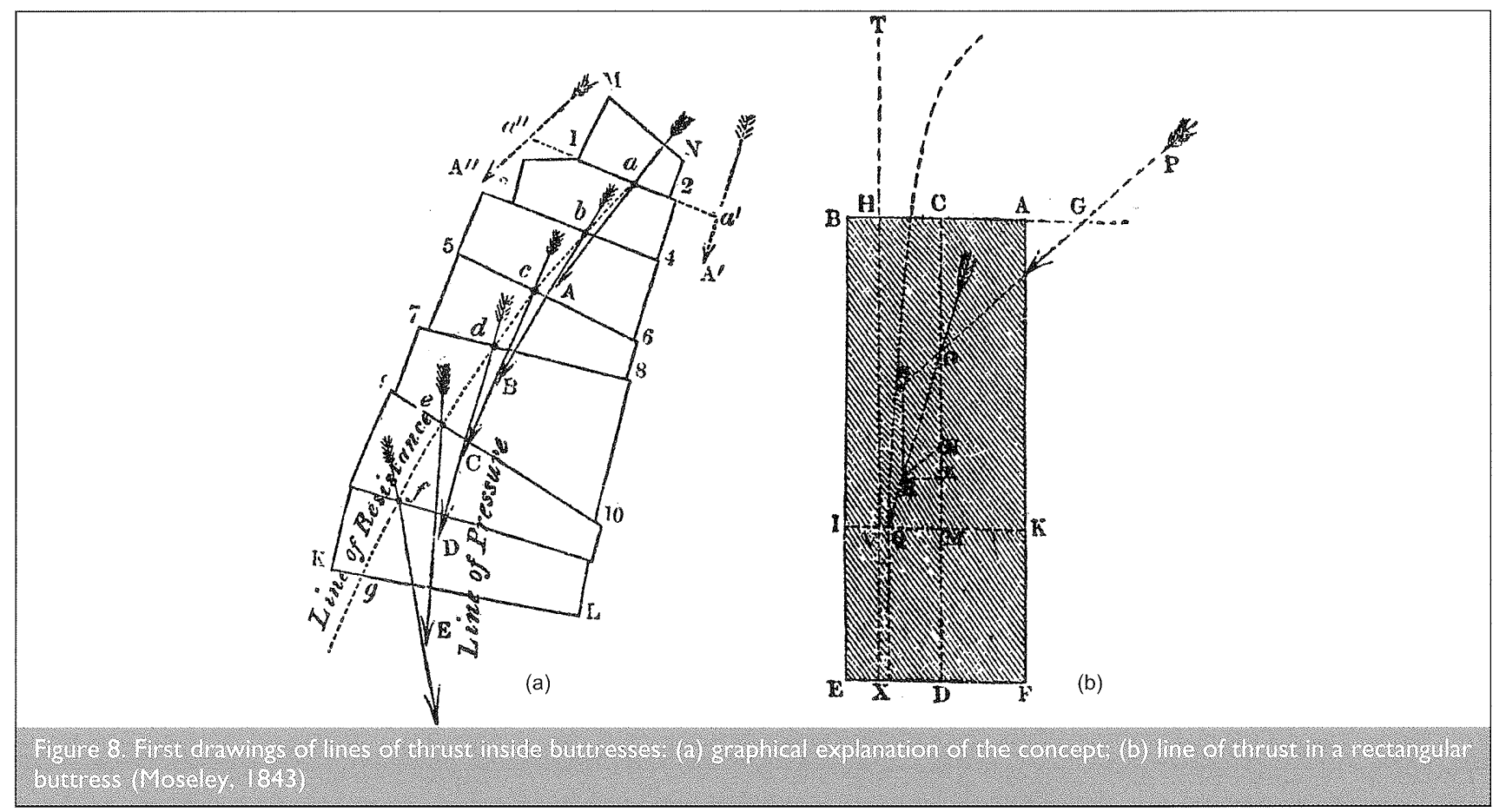


Moseley studied the form of the line of thrust through a rectangular buttress (Figure 8(b)) and realised that a buttress of infinite height may, nevertheless, have a finite thickness. In fact, this had been discovered by the French engineer Danyzy in 1732, who realised that this property justified the use of safe geometrical design methods that did not consider buttress height (Huerta, 2004). This discovery is, however, usually attributed to Moseley.

Moseley also studied the safety of arches and his approach was completely different from the French approach. Being well aware that the safety of every joint depended mainly on the position of the line of thrust (centre of resistance) he defined his 'modulus of stability' as 'the nearest distance which the line of resistance [line of thrust] approaches the extrados' (Moseley, 1843). Moseley is here considering safety as a matter of geometry. It is true that, for usual arch forms, the danger is that of overturning, since the possibility of a sliding failure is concentrated only in a very few cases, for example when the point of application is near the top of the buttress, a particular case that Moseley studied.

Moseley made every effort to explain the usefulness of his theory and provided many examples. However, the complicated formulae at which he arrived (sometimes occupying several lines) must surely have discouraged many engineers and architects. Like many of his contemporaries, Moseley was interested in the rationality of Gothic forms. He studied the high strength of pointed arches (Figure 9(a)) and also investigated the form of a Gothic stepped buttress with (nearly) constant stability throughout its height (Figure 9(b)).

Finally, Moseley explained how to deal with compound buttresses such as the one shown in Figure $9((\mathrm{c}))$. He reduced the problem to that of a continuous wall extending the material between the counterforts and obtained a continuous wall with two different specific weights. He then applied the same considerations as for a simple buttress. This was equivalent to considering the wall-plus-counterforts system as a monolith, since it is the line defined by the external boundary of the counterforts that is considered as the axis of overturning.

W. J. M. Rankine exploited all the consequences of Moseley's contribution and proposed a complete theory of masonry buttresses (Rankine, 1858). Rankine stated the two conditions of stability of a plane joint as follows.

The obliquity of the pressure must not exceed the angle of repose. The ratio which the deviation of the centre of pressure from the centre of figure of the joint bears to the length of the diameter of the joint traversing those two centres, must not exceed a certain fraction, whose value varies, according to circumstances, from one-eight to three-eighths.

He named the first 'stability of friction' and the second 'stability of position'. Rankine then adopted the same geometrical approach of safety as Moseley, but defined the position of the line of thrust relative to the dimensions of the joint, fixing the maximum deviation from the centre of the joint as $q t$, where $t$ is the length of the joint. The parameter $q$ serves as the means of defining the safety required. Rankine stated that this ratio should be obtained through a consideration of strength of materials, but then added

nevertheless, an approximation to that position can be deduced from an examination of the examples which occur in practice, without having recourse to an investigation founded on the theory of the strength of materials.

He then discussed possible values of $q$ and established, as a lower limit, the value usually adopted for retaining walls: for British engineers $q=3 / 8=0 \cdot 375$ and for French engineers $q=$ $3 / 10=0 \cdot 3$. Rankine went on to remark

In the abutments of arches, in piers and detached buttresses, and in towers and chimneys exposed to the pressure of the wind, it has been

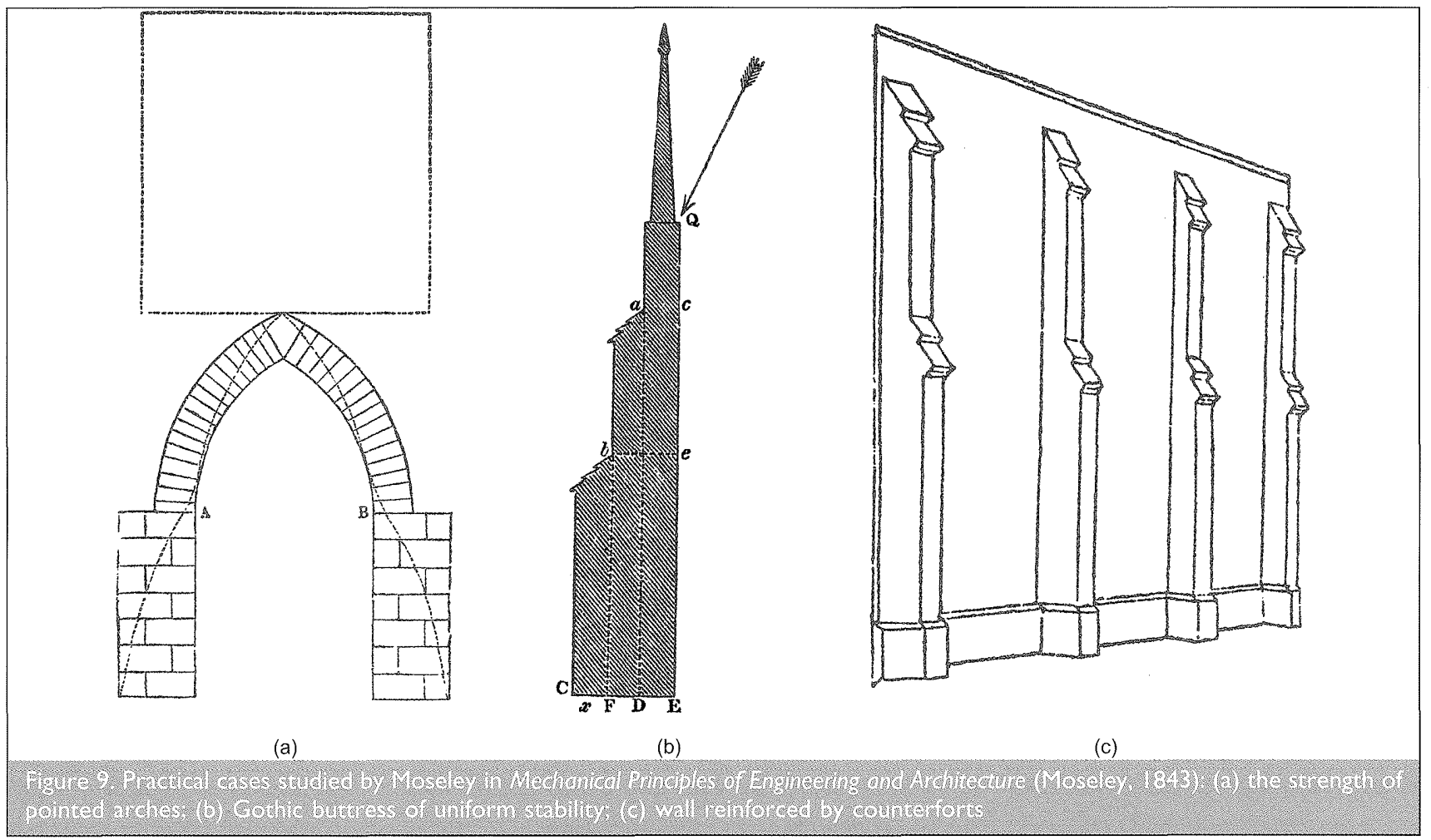


found by experience to be advisable so to limit the deviation of the centre of pressure from the centre of figure, that the maximum intensity of the pressure, supposing it to be an uniformly varying pressure, shall not exceed the double of the mean intensity.

This means that the point of application of the thrust must lie within the core of the cross-section, so that all the stresses must be compressive, and Rankine gave a table relating the shape of the section to the parameter $q$, which defines the limiting size of the core that ensures safety, as explained above. The minimum value is for a circular solid section where $q=1 / 8$. It should be noted that here Rankine mixes the notion of a geometrical factor of safety with a limiting value of strength. In fact, the problem is not the occurrence of certain tensile stresses or even of the value of compressive stresses, but the 'stability of position'. There may be a stability condition that is dangerous despite very low compressive stresses: the compressive stress resultant may be near the border with low stresses. The middle-third rule for rectangular sections is popular because it appears to be a strength condition, compatible with the 'elastic' approach; in fact, the consideration of no tensile stress leads to a strict geometrical condition. It is this geometrical condition that assures safety, whether the engineer or architect is aware of this or not.

Rankine was also interested in the intrinsic geometrical properties of buttresses related to stability. For this, he invented the moment of stability (Figure 10(a)) as a geometrical property of the buttress, independent of the force or forces it resists, which he defined thus.

The moment of stability of a body or structure supported at a given plane joint is the moment of the couple of forces which must be applied in a given vertical plane to that body or structure in addition to its own weight, in order to transfer the centre of resistance of the joint to the limiting position consistent with stability.

The mathematical expression for a horizontal joint is $M_{\mathrm{s}}=W(q$ $\left.\pm q^{\prime}\right) t, q^{\prime} t$ being the distance from the vertical line passing through the centre of gravity of the masonry above the joint to the centre of the joint $\mathrm{C}$. The value of the property denoted by \pm depends on the position of this vertical line, to the right $(+)$ or the left $(-)$ of C (Figure 10(b)). Rankine then explained that the moment of stability is in fact (see Figure 10(b))

the moment of the couple, which, being combined with a single force equal to the weight of the structure, transfers the line of action of that force parallel to itself through a distance equal to the given horizontal distance of the centre of resistance from the centre of gravity of the structure.

While this is all simple statics, Rankine's approach permits the engineer to consider the relative benefits of certain forms of buttress from the point of view of stability. Figure 11 shows several buttress profiles. If the moment of stability of the rectangular buttress (Figure 11(a)) is taken as 1, then the other buttresses (with the same volume) have moments of stability of (b) 1.71 , (c) 1.63 and (d) $2 \cdot 18$ (profile (d) corresponds to Vétheuil Church (e)). The efficiency of the Gothic stepped buttress is thus demonstrated but, of course, it complicates the process of building and the need of maintenance to prevent the ingress of rainwater.

Rankine went on to state that a structure formed from a series of masonry blocks would be safe if, at every joint, the two conditions of stability of friction and position were satisfied. This can be done in the most convenient way by drawing the line of thrust (Figure 12(a)). He then went into the detail of obtaining this curve, both geometrically (predating by 8 years the graphical design methods published by Culmann) and analytically, for the buttresses of buildings (i.e. slender buttresses subjected to the action of concentrated loads (Figure 12(b)). He first developed the general equation for the line of thrust and then studied several practical cases. The exposition is rigorous and worth studying even today.

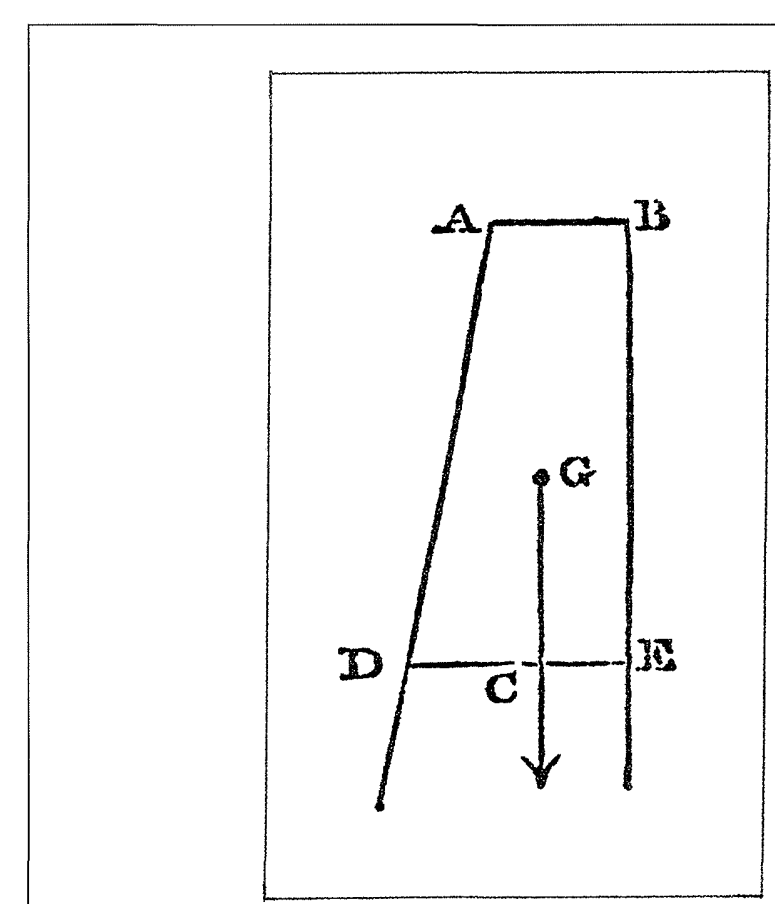

(a)

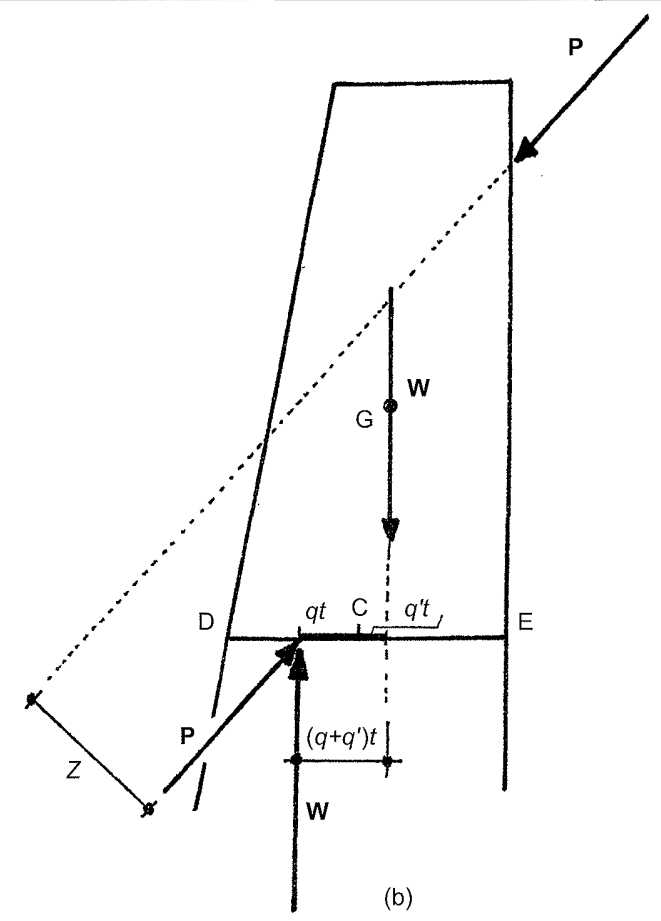

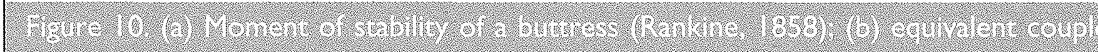




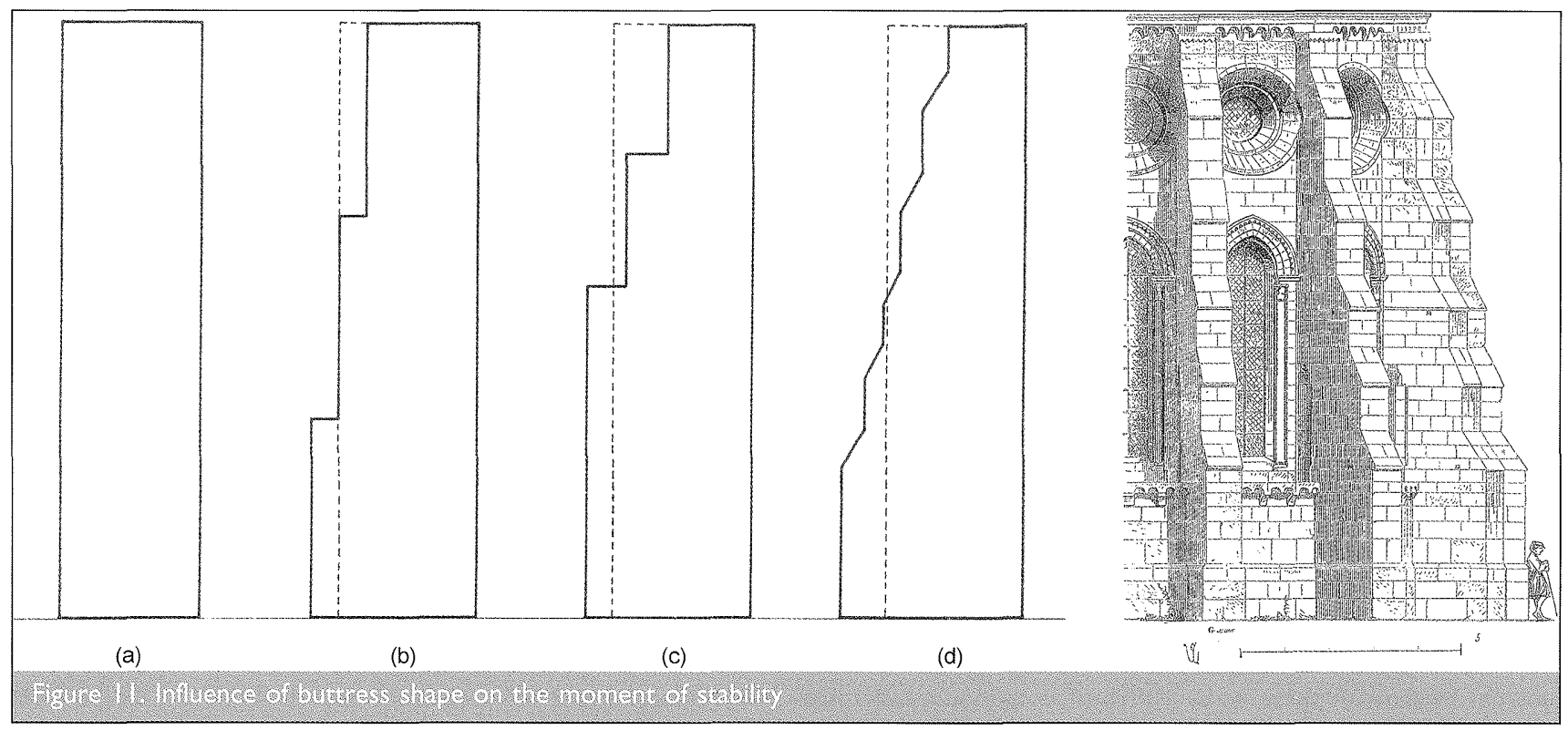

As for the compound buttress, Rankine, like Audoy, considered (implicitly) the buttress 'divided' into two parts: the 'counterforted wall' having the full thickness of the buttress and the wall between the counterforts. He computed the moment of stability as the sum of the moments of stability of both parts (Figure 12(c)). He then calculated the thickness of the equivalent uniform wall (i.e. a continuous wall having the same stability) and compared the volume of masonry in both cases. He concluded that 'there is a saving of masonry (though in general but a small one) by the use of counterforts'. In fact, Rankine's assumption is equivalent to considering that there is no connection at all between the two parts of the buttressed wall and so gives an unnecessary margin of safety. Rankine also treated a number of other forms of masonry construction, including the buttressing of a groined vault (Figure 12(d)).

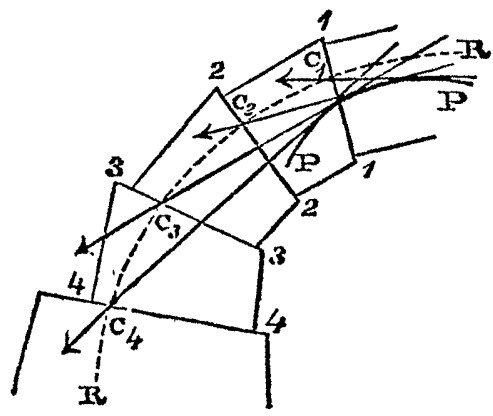

(a)

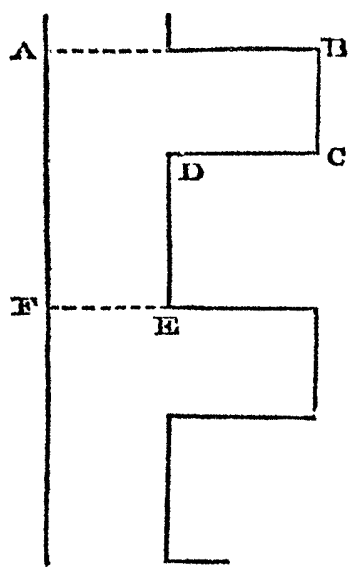

(c)

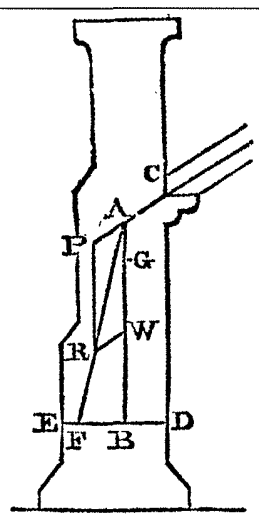

(b)

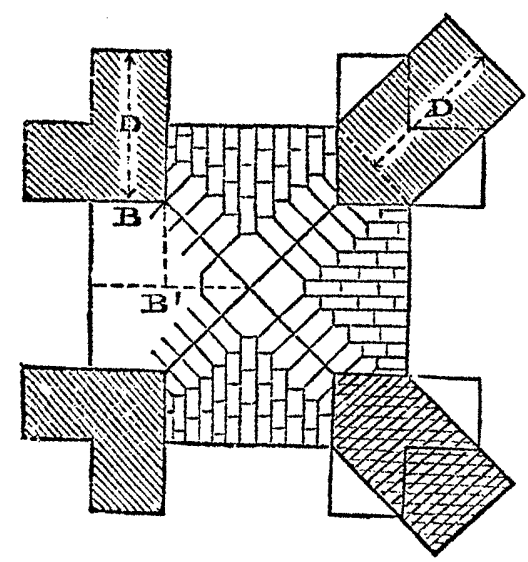

(d) 


\subsection{Design and analysis of masonry buttresses and buildings c. 1900}

In the last quarter of the nineteenth century, both approaches the French approach using the coefficient de stabilite, which served mainly to check the stability at the base of the buttress, and the English geometrical approach - coexisted. The main problem was to obtain the vault thrust; verification of the safety of the buttress was made afterwards.

The analysis and design of complete buildings proved to be a much more complicated affair than, for example, the design of masonry bridges. Masonry bridges usually have a barrel vault and the abutment walls are rectangular buttresses (solid, or hollow with spandrel walls). In the case of a building, say a neoGothic church, the system of vaults, walls perforated by great windows and triforia, flying buttresses and external buttressing formed a complex structure that had to be analysed if any numerical results were to be obtained. This was rarely done apart from very particular cases. In general, the traditional geometrical rules continued to be used to establish overall dimensions and the stability was then checked using one of the above mentioned methods.

Karl Mohrmann, an architect of the Hannover school, set himself the task of explaining the behaviour of complex Gothic buildings using the conventional approach to the theory of structures. His additions to the third edition of Lehrbuch der gotischen Konstruktionen (Manual of Gothic Construction) (Ungewitter and Mohrmann, 1890) contain a detailed statical analysis of all the elements of a Gothic structure. His approach was to look for a reasonable state of statical equilibrium among the infinitely many possible in such highly hyper-static structures. With regard to buttresses, Mohrmann added a complete chapter on the form and depth of buttresses (Form und stärke der widerlager). This chapter runs to 50 pages and includes many figures, tables and plates; it constitutes by far the most complete study on buttresses ever written. He also added substantial notes and drawings on buttresses in a chapter on churches in section and elevation (Die kirche im querschnitt und aufriss). He studied churches with one nave, hall churches and churches with three naves of different heights, and in each case made calculations of the stability of the buttress system.

Mohrmann was fundamentally concerned with the problems of statical equilibrium (i.e. of the possible paths or lines of thrust of compressive forces that could explain the behaviour of the buttress system as a whole). He began by studying the simple buttress considering the shape of thrust lines and the possibility of failure in sections other than the base. As shown in the lefthand drawing of Figure 13(a), he was concerned with the equilibrium of an intermediate pier; in the right-hand sketch he drew attention to the possibility of failure at three different sections (I, II, III). To ensure safety at each joint, he accepted Rankine's condition that all the stresses must be compressive (i.e. the thrust must be contained within the core of the crosssection). Figure 13(b) illustrates different families of planes of joints in order to construct the line of thrust.

However, the emphasis through all Mohrmann's chapters and subsequent notes is always on statical equilibrium. For example, he studied the problem of hall churches with adjacent vaults of different spans and how to equilibrate the thrusts so that the loads may enter more or less vertically into the piers (Figure 14). For analysis of complex buildings, he used the equilibrium approach extensively. He first divided the structure into several fundamental elements or 'blocks' (main vaults, aisle vaults, flying buttresses, walls and triforia, buttresses, etc.). He then studied the conditions of equilibrium for every element, 'assembled' the blocks in equilibrium and then checked that, at every joint, the thrusts were contained within the masonry. Figure 15 shows a selection of the illustrations of different plates indicating the level of detail of his analysis. However, it appears than Mohrmann was not satisfied with the study of global equilibrium; he also addressed some particular problems

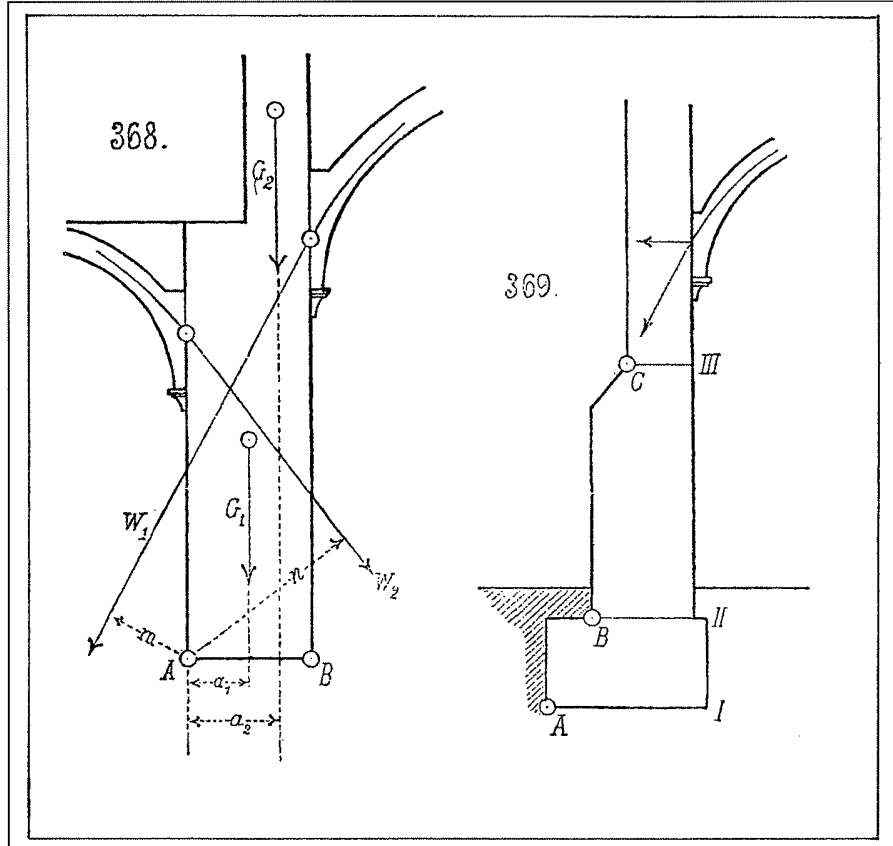

(a)

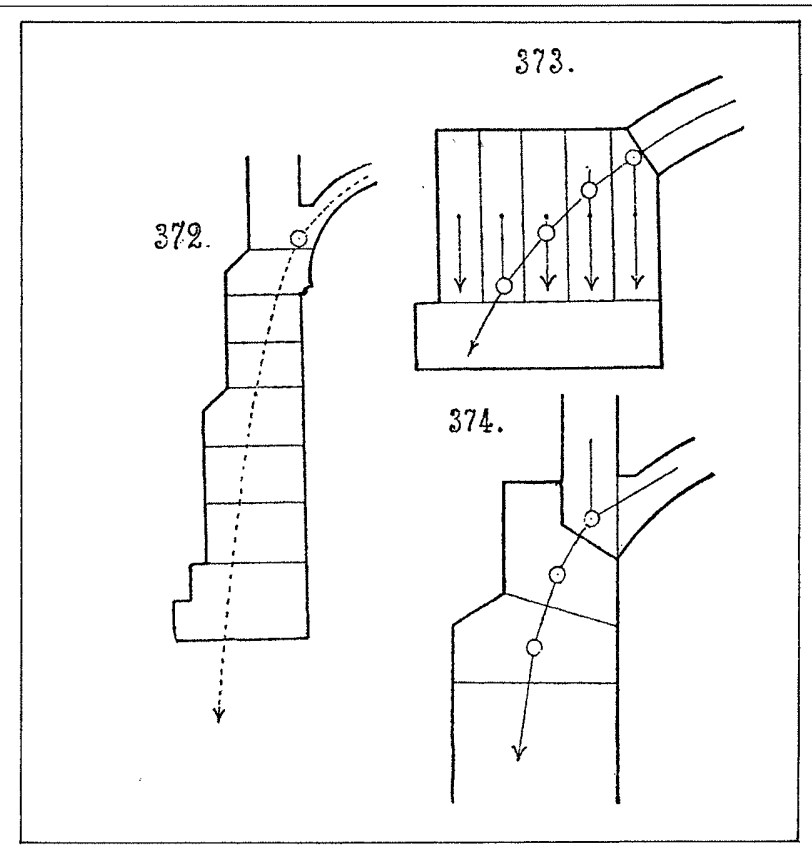

(b) 


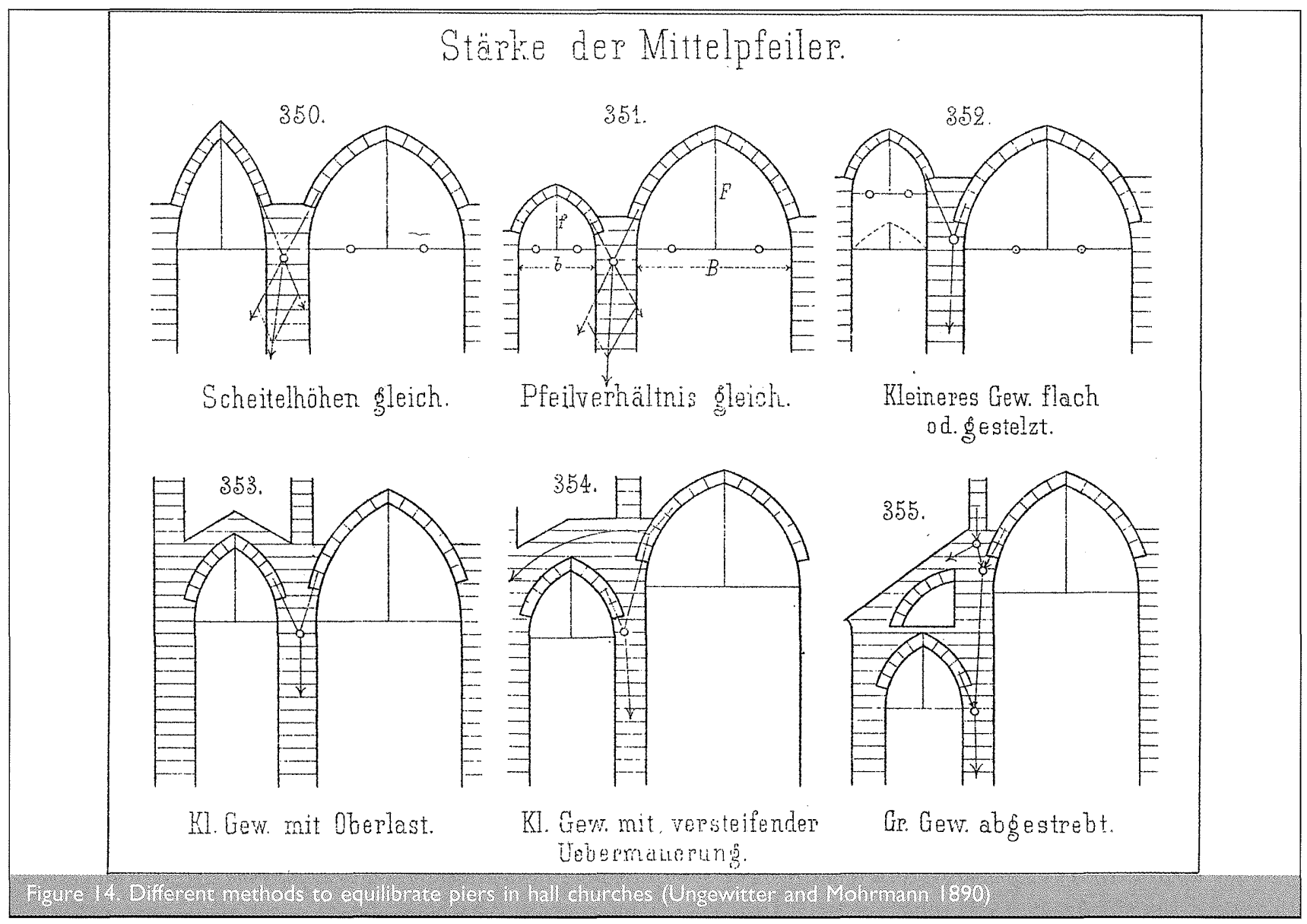

not previously researched. Figure 16 shows one of these problems: the effect of diminution of section in a triforium and how the loads may pass through the masonry. Among his many other examples are the stability of slender mullions in windows and the statics of Gothic spires. Mohrmann's additions form a complete manual on the statics of Gothic churches.

Mohrmann is singular for both his extension and depth, but he was not alone in using statical equilibrium with graphical statics to analyse the stability of masonry buildings. In Europe around 1900 , it was current practice among architects and engineers to use this approach when analysing many structural problems; the work of Pierre Planat in France deserves particular mention (Huerta, 2008).

However, for the theoreticians deeply steeped in the assumptions of classical elastic theory, this equilibrium approach was considered, at best, a gross approximation of 'actual' structural behaviour. For them, answers could only be found by solving the three sets of equations for equilibrium, elastic material and compatibility. Those equations had been long established (for example by Navier in 1826), but they were impossible to solve for masonry structures (Heyman, 1998b). Nevertheless, the conviction that the only way to find the 'real' state of the structure was by solving the elastic equations was considered indisputable - an article of faith, in fact.

\section{THE TWENTIETH CENTURY: LIMIT STATE ANALYSIS}

The equilibrium analysis of Mohrmann hinted at the heart of the problem. The buttress system forms part of a complex hyper- static structure and therefore its internal forces are part of a complex spatial system of equilibrium. The usual distinction between a vault, which thrusts, and a buttress, which counterthrusts, is useful for simple systems (as in bridge design or the case of a single nave church) but, in the case of a complex church, overall equilibrium needs to be considered. Heyman (1967-1968) noted how consciously and freely Mohrmann handled the different possible equilibrium solutions. Indeed, Mohrmann proposed a simplified method to obtain a satisfactory value for the thrust of a flying buttress (Figure 15(c)). Given a certain value for the vault thrust (which, in fact, varies between close limits), he assumed (arbitrarily) that the horizontal component of the thrust from the flying buttress $(B)$ is horizontal and acts at a certain height. Taking moments about the centre of the pier, it is possible to calculate the value of $B$ and then to check the passage of the thrust through the masonry of the buttress system (if this is not the case, it is easy to make another trial). Mohrmann made no statements about the elastic properties of the material or about compatibility conditions. This was intolerable for engineering scientists, but any architect or engineer would have felt that this was a valid way - indeed the only way - to handle the infinitely many equilibrium solutions. In fact, the example of Figure $15(\mathrm{c})$ is deliberately simple - a far cry from the real case of Beauvais Cathedral with its complex system of flying buttresses, intermediate piers and a third, hidden, horizontal 'flying buttress' in the form of a wall over the transverse arches of the aisle vault (Figure 17(a)). Benouville made a statical analysis of Beauvais in the concours he made to become architecte diocésain (Benouville, 1891) (Figure 17(b)). His analysis (épure de stabilité) was presented without 


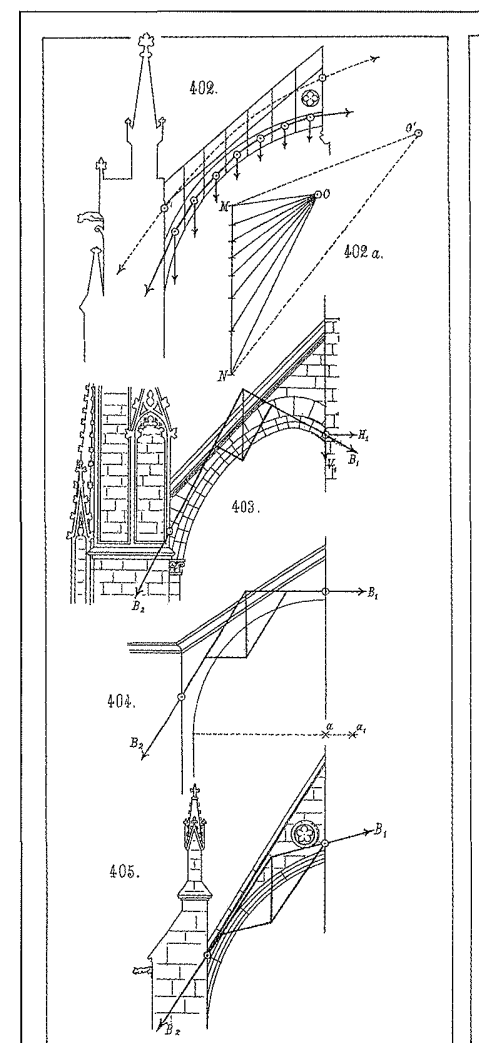

(a)

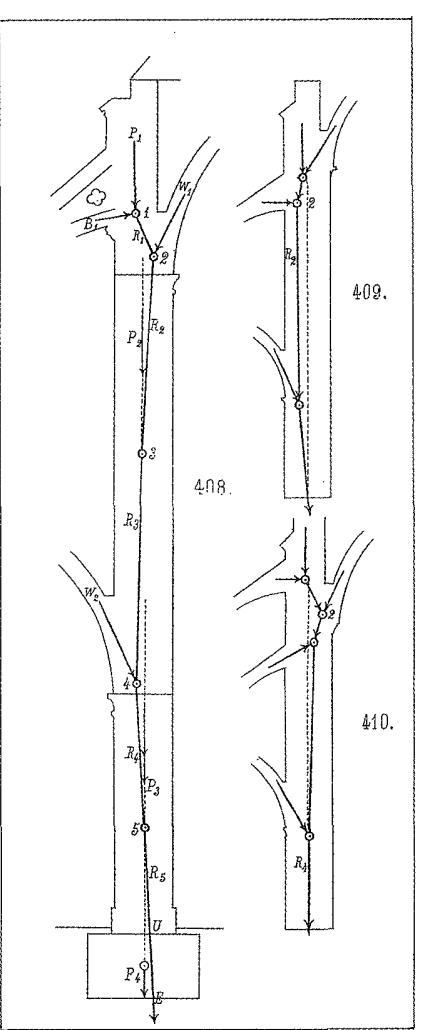

(b)

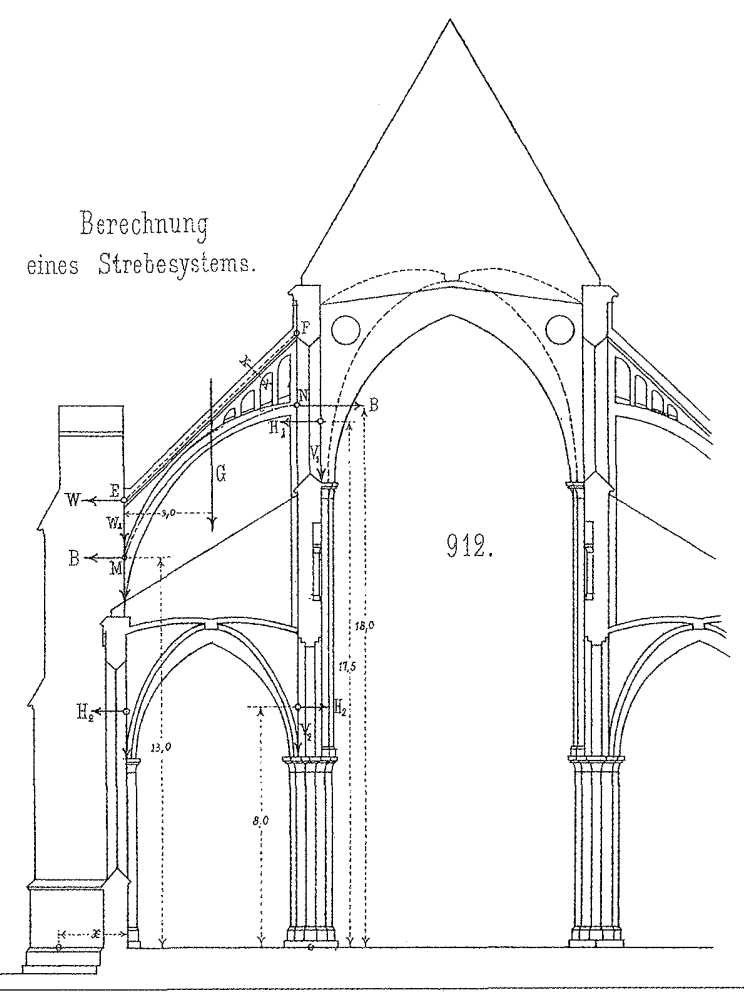

(c)

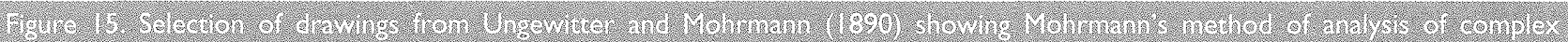

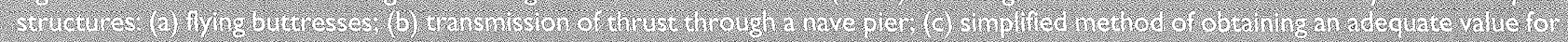

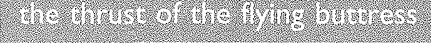

explanation as a well known and usual procedure (some of his results have been discussed by Heyman (1967-1968); the force polygons represent the equilibrium between certain parts or 'blocks' of the structure). It should be stressed that Benouville presented one solution of equilibrium of internal forces within the masonry. He did not claim that this was the 'true' or 'actual' state of the structure and it is evident that it would not be difficult to find other safe equilibrium states.

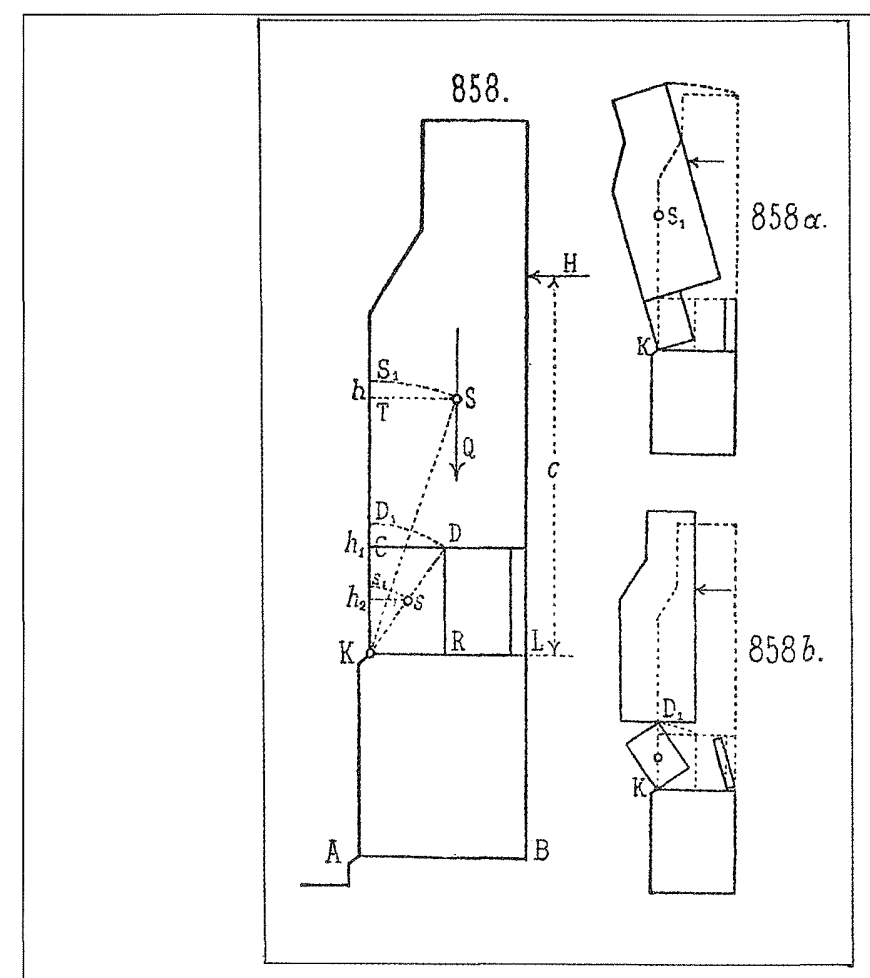

(a)

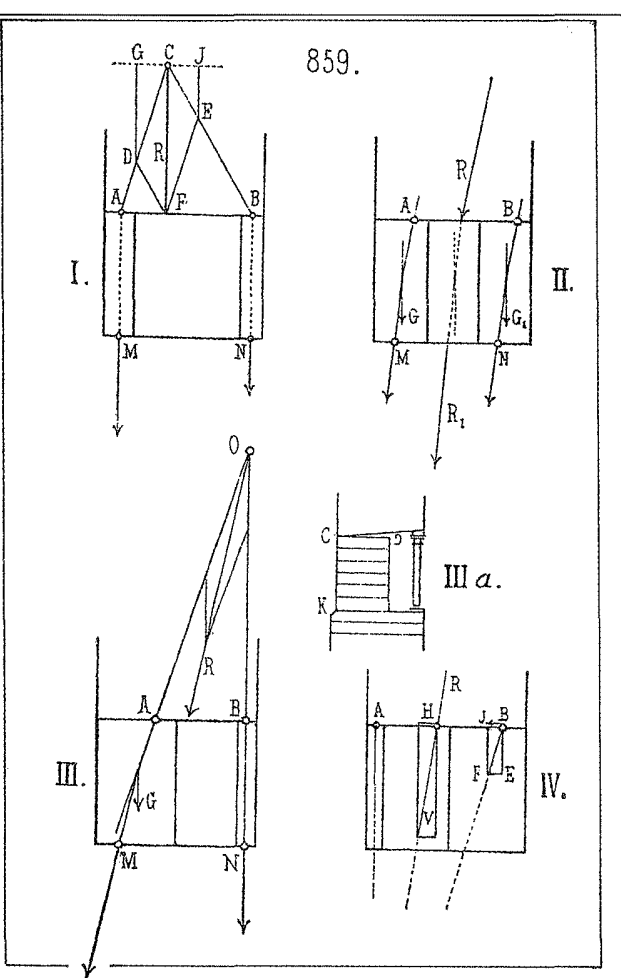

(b) 


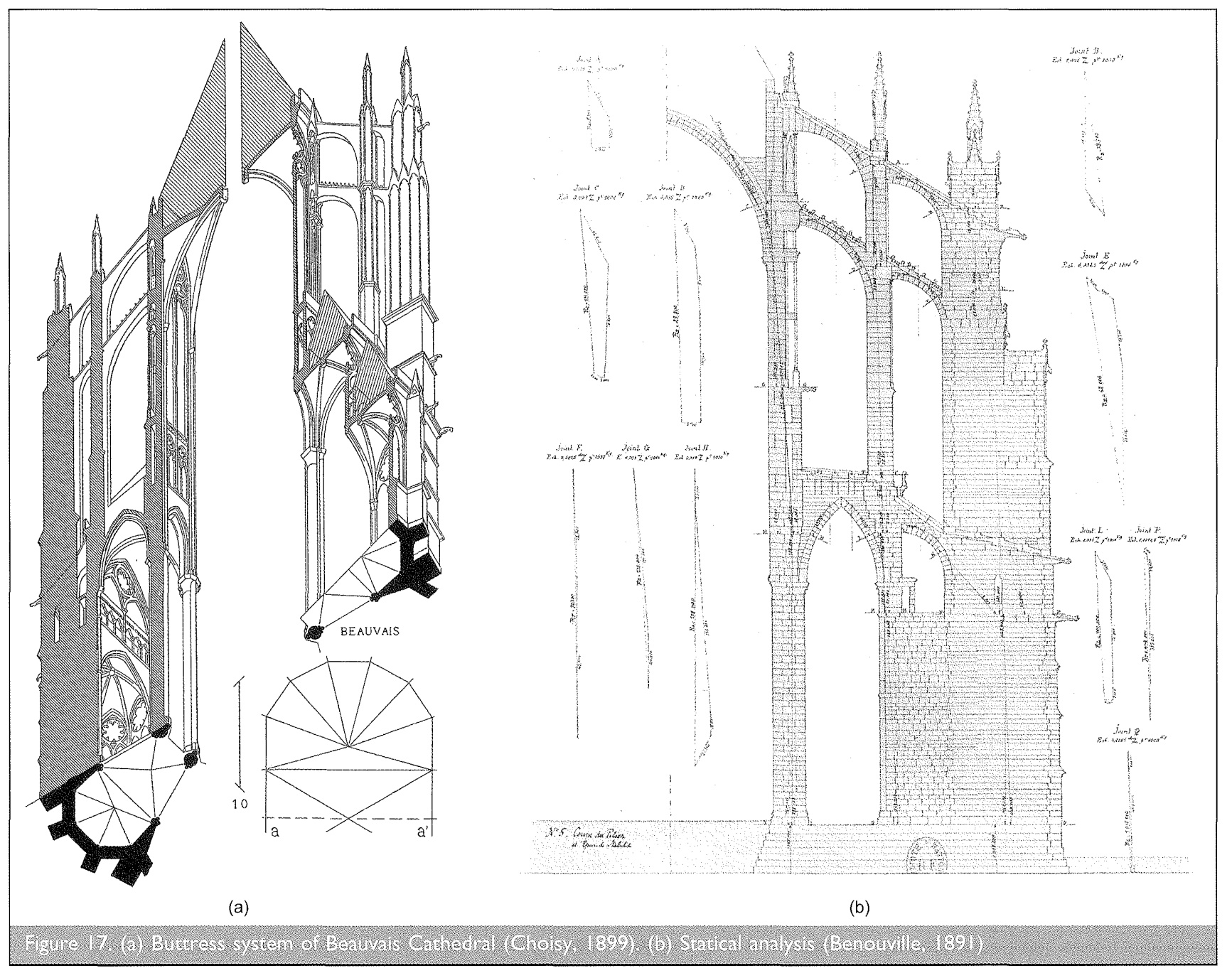

What is, then, the actual state of a masonry structure? How can its safety possibly be ascertained if there are doubts about the true state of internal forces?

The solution to these problems came in 1966 with publication of a milestone paper in the theory of masonry structures (Heyman, 1966). In his paper 'The stone skeleton', Heyman (1995) realised that if the material satisfied certain conditions - namely an infinite compressive strength, zero tensile strength and with sliding at the joints impossible - then the whole theory of masonry structures could be rigorously incorporated within modern limit state analysis (LSA) (or plastic design) of structures. These same assumptions had already been made explicitly by many nineteenth century engineers (for example by Moseley in 1843) and they are logical and easy to check. The first, infinite compressive strength, although unsafe in theory (since no real material has infinite strength) is true enough in practice as the actual stresses in masonry buildings are very low. (Benouville had been surprised to find a stress of only $1.3 \mathrm{~N}$ / $\mathrm{mm}^{2}$ in the nave piers of Beauvais Cathedral, which support the world's highest Gothic vaults.)

If the material masonry structure obeys the three equilibrium conditions, the yield surface is formed by two straight lines and the condition that must be satisfied at every joint is that the internal force - the thrust - should be contained within the masonry. (The yield surface plots the relationship between the stress resultants $N$ (normal force) and $M$ (bending moment) at the limit state of the joint. The limit for the eccentricity of the load is half the depth of the section $h$, therefore the straight lines $N h= \pm M$ define the permissible region for the values $N$ and $M$.) When the thrust touches the boundary, a hinge is formed. It is this possibility of forming hinges that is crucial to translating the fundamental theorems of LSA from steel to masonry (an extraordinarily imaginative and lucid explanation is given by Heyman (2008)). From these theorems, the most 'fundamental' is the safe theorem: if it is possible to find a set of internal forces in equilibrium with the external loads that satisfies the yield condition, then the structure is safe (will not collapse). The crucial point is that this 'set of internal forces in equilibrium' need not be the 'actual' state in the structure. In fact, the question as to what is the actual or real state in a hyper-static structure (in any material) is nonsensical. Minute changes in the boundary conditions produce enormous changes in the set of internal forces in equilibrium with the loads. This matter has been discussed in depth by Heyman in many publications (e.g. Heyman, 2005) and need not be repeated here.

So, it turns out that Mohrmann's static equilibrium approach is entirely valid. The first task of the analyst in studying a complex buttress system is to find a reasonable equilibrium state that could serve to answer the problem in question. General questions of the type 'Is a cathedral (which has stood for six centuries) safe?' are unnecessary. There must be some evidence of damage or danger to trigger the expensive process involving expertise and, because there is no universal, standard way of 
approaching the analysis of historical masonry structures, the expert analyst will focus the analysis precisely on the problem or problems observed.

This review of the history of buttress design has permitted us to single out the principal problems regarding their analysis and estimations of structural safety. However, some final comments can be made, within the frame of LSA, which will serve to complete the picture and define the concept of safety and the analysis of compound buttresses more precisely.

\section{I. Geometrical coefficient of safety}

One of the main conclusions of the application of LSA is that the safety of masonry structures is only a matter of geometry and it turns out that Rankine's approach of constraining the position of the thrust to a certain region within the section is completely correct. Huerta and López-Manzanares (1997), however, considered it more convenient to use a different way of determining the location of the thrust. This consists of dividing the halfdiameter $\mathrm{AC}$ by the distance from the point of application of the thrust to the centre of $\mathrm{C}(x)$ (Figure 18(a). This method obtains a geometrical coefficient of safety, $c_{\mathrm{g}}$ of $t / 2 x(=1 / 2 q)$, which represents the fraction of the central area of the buttress that may contain the thrust. In this way, a geometrical coefficient of 2 means that the thrust is located at the boundary of the middle central half of the buttress, a coefficient of 3 means that it is at the boundary of the middle third, and so on. Different sections will have different geometric coefficients of safety will be a minimum in the overturning direction of the buttress. In Figure 18(b) this takes place at the base.

This definition of the geometrical coefficient of safety has the advantage of being similar to the geometrical factor of safety defined by Heyman $(1969,1982)$ for masonry arches. For bridges, Heyman suggests geometrical factors of safety of around 2. The value of 3 used by Rankine when considering the compressive stress in the whole section is more restrictive, but still seems low when compared with factors actually observed in many Gothic buildings. It is not uncommon to find geometrical coefficients of 4 or higher for rectangular buttresses. To discuss actual values of the geometrical coefficient of safety $c_{\mathrm{g}}$ it is necessary to study:

(a) the actual collapse load of a masonry buttress; and

(b) the influence of the buttress leaning on the safety of the entire vault system.

\subsection{Collapse of an isolated buttress}

One of the best approaches to estimate the safety of a structure accurately is to calculate its collapse load. In all the previous analyses it has been implicitly considered that the buttress would not collapse. If it were to collapse, it is assumed it would do so at one of the joints between the sections into which the buttress is imagined to be divided (for example, joint $\mathrm{C}$ in Figure 13(a)). However, although it is useful to consider the buttress as a system of rigid blocks in order to study the internal forces, the fact is that the buttress is formed from stones or bricks bonded together with weak mortar. If a buttress is caused to overturn at a certain boundary (say at the base) it will probably fracture and a masonry wedge will remain at the base. The weight of this wedge would not have been taken into account for the computing of its moment of stability and, therefore, the calculated collapse load would represent an upper bound. This was well known by nineteenth century engineers and the history of the interest in this phenomenon has been treated elsewhere (Huerta, 2004; Huerta and Foce, 2003).

It was again Heyman who first studied the possibility of fracture in thick walls and towers made of nonmonolithic masonry. In 1992, he showed how to approach the problem and calculated the form of the surface of fracture in the collapse of a leaning tower (Heyman, 1992). Shortly afterwards, in 1993, an unpublished manuscript from around 1800 by the Spanish engineer Joaquin Monasterio was discovered (Huerta and Foce, 2003). Monasterio had also studied the formation of fracture surfaces in buttresses (Figure 19) and considered that in buttresses made of ashlar masonry, the fracture would be

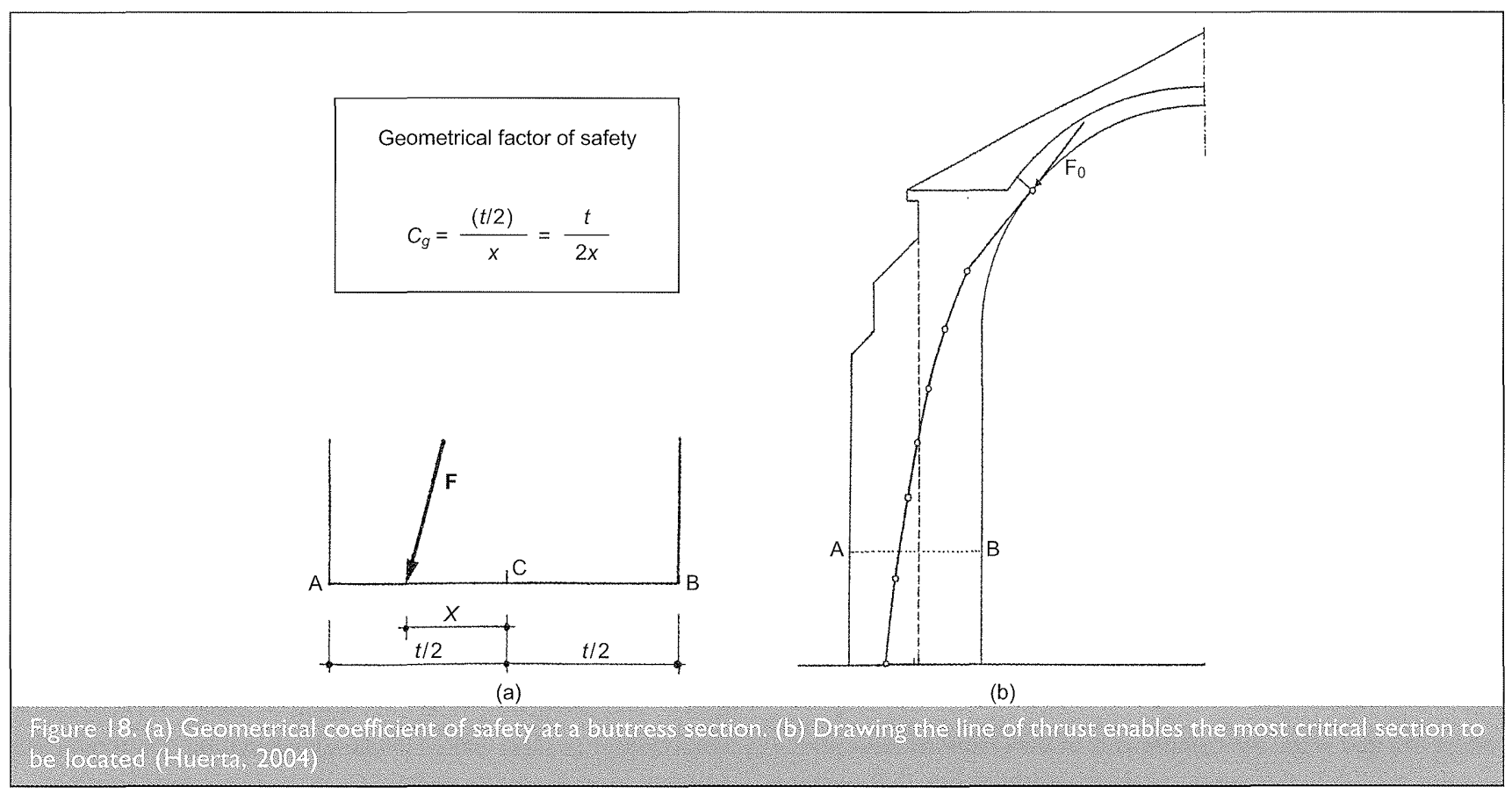




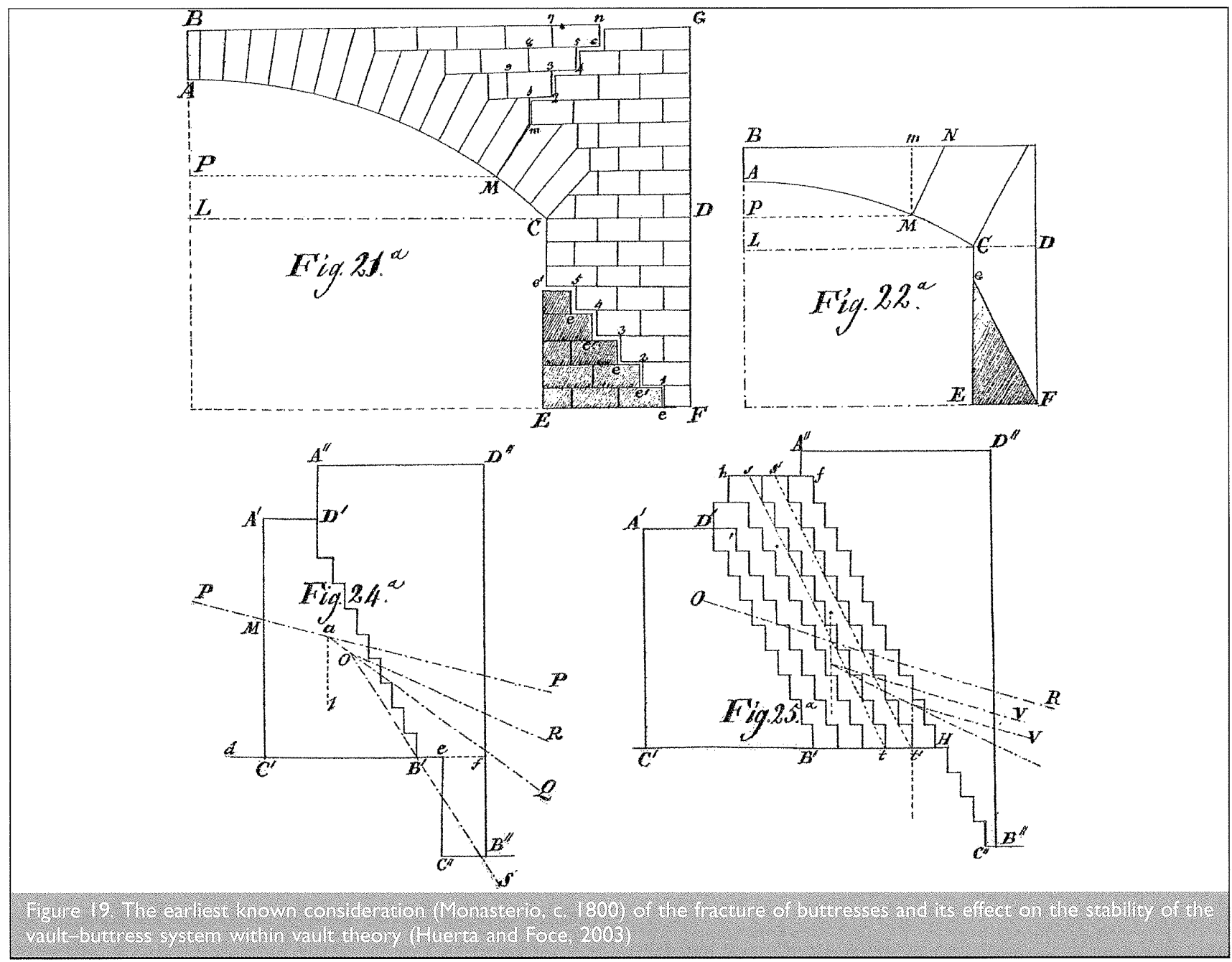

determined by the form and size of the blocks (Monasterio, c. 1800).

In collaboration with John A. Ochsendorf, this problem was revisited in 2001. When conducting research under Heyman at the University of Cambridge, Ochsendorf used a numerical approximation to obtain the surprising result that the fracture of a rectangular buttress was planar. This elegant demonstration of planar fracture was made known to the author in a private communication (Heyman, 2001) and in Ochsendorf's doctoral thesis (Ochsendorf, 2002). It was published in Spanish and English (Ochsendorf et al., 2003, 2004) and, more recently, Ochsendorf and Lorenzi (2008) have contrasted previous studies of the fracture of buttresses with numerical models of block systems.

The statics of fracture of certain buttresses is extremely simple. Once the point of origin of the fracture has been located, the line of thrust must pass through the boundary of the core (the middle third for a rectangular section). The angle of the plane of fracture can then be obtained by means of Equation 1 (Figure 20(d)), which establishes the equilibrium of the inferior masonry wedge

$$
\left(W_{0}+W_{\mathrm{c}}\right)(t / 3)=H h
$$

where $W_{\mathrm{o}}$ and $H$ are the components of the resultant force above section $\mathrm{AC}, W_{\mathrm{c}}$ is the weight of the masonry wedge that remains on the base (considering $1 \mathrm{~m}$ breadth is $W_{\mathrm{c}}=(1 / 2)(h t) \gamma, \gamma$ being the specific weight of the masonry), $t$ is the depth of the buttress at $\mathrm{AB}$ and $h$ is the height of the wedge. Algebraic manipulation yields

\begin{tabular}{|c|c|}
\hline 17 & $\tan \alpha=\frac{h}{t}=\frac{W_{0}}{\left[H-\left(\lambda t^{2} / 6\right)\right]}$ \\
\hline
\end{tabular}

Let us consider an actual masonry buttress subject to a concentrated load $F$ of magnitude inferior to the actual collapse load. The value of $F$ being known, it is a simple matter to draw the thrust line, dividing the buttress in hypothetical blocks separated by horizontal joints. For the case where there is no fracture, the thrust at the base will pass through point $F$ in Figure 20(b). In general, at section AC, a fracture will begin to form when the stress at the inner face of the buttress falls to zero, or when the line of thrust reaches the boundary of the middle third. At point B there is an abrupt change of curvature of the line of thrust and the curved line of thrust (above section $\mathrm{AC}$ ) becomes a straight line (below section $\mathrm{AC}$ ). The wedge $\mathrm{CGH}$ will separate from the buttress and the angle of fracture can be calculated by means of Equation 2. (It should be noted that the angle of fracture depends only on the loads above section AC.) As a result, the thrust at the base becomes displaced from point $\mathrm{E}$ to $\mathrm{F}$, and the geometrical coefficient of safety experiences a reduction of around 20\%. This is a considerable reduction. The collapse load $F_{\mathrm{c}}$ can be calculated by statical considerations 


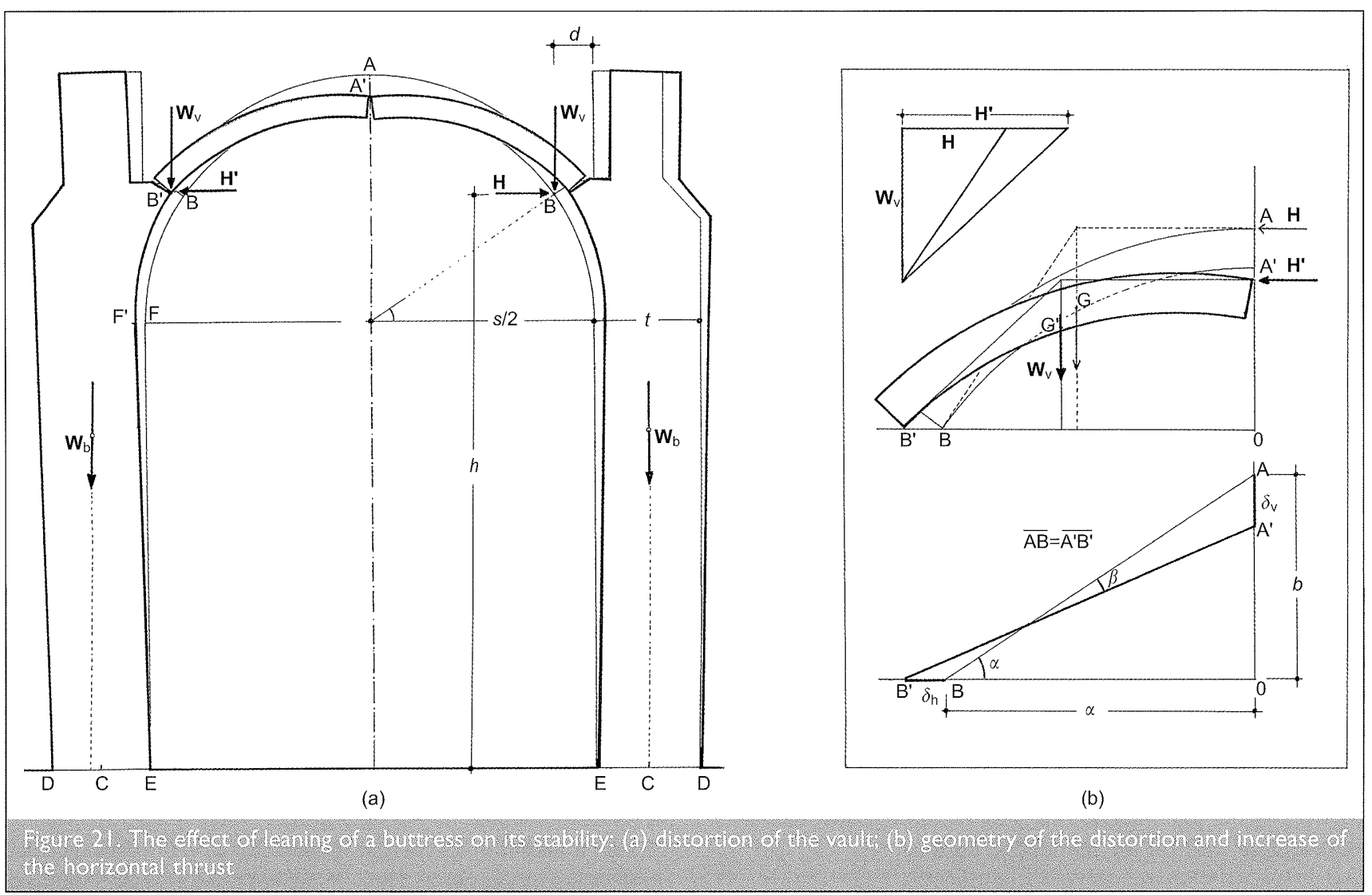

slenderness of 6 . This will reduce the moment of stability by 30\%. This 'new' distorted arch would then crack and adopt the form shown in Figure 21(b), where the deformations have been exaggerated to show the geometrical parameters. There is a simple relationship between the horizontal displacement $\delta_{\mathrm{h}}$ due to leaning and the vertical drop $\delta_{\mathrm{v}}$ of the crown. A simple quadratic equation may be written, assuming that the hinges will not change and that the distance $\mathrm{AB}$ remains constant during the movement. In this case $\delta_{\mathrm{h}}=160 \mathrm{~mm}$ (i.e. a total opening of $320 \mathrm{~mm}$ or $\mathrm{s} / 22$ ) and $\delta_{\mathrm{v}}=260 \mathrm{~mm}$. The original horizontal thrust $H$ increases by $20 \%$ in the distorted vault.

It is now possible to check the stability of the inclined buttress for the new thrust. It turns out that the geometrical coefficient of safety has been reduced to $c_{\mathrm{g}}=2 \cdot 3$. This implies, theoretically, that there would be a cracking of the buttress at the base and a further reduction of the geometrical safety to $c_{g}=2 \cdot 1$. The situation is far from favourable as any increase in the vault thrust would give rise to further leaning of the buttress and possible collapse. (It should be noted that the buttress would not overturn at this leaning as its weight would pass within the base during the 'snap-through' collapse of the vault; this is the reason why, in ruins, the walls are still standing though the vaults have collapsed.) In fact, this is what happened at Rois (Figure 22). At an indeterminate date in history, the chapel had been given added counterforts (not bonded to the wall) and this apparently stopped the movement. However, abandonment of the building in the 1960s and the entry of water, etc. provoked the collapse that began in the 1980s with the fall of a central part of the vault and culminated in the 1990 s with collapse of $70 \%$ of the vault. A contemporary master builder from the beginning of the eighteenth century would have objected to the thinness of the walls. However, a modern architect and engineer would have considered the initial design safe because the buttress had been designed using design criteria even more conservative than those recommended by Rankine and subsequent authors, and it had a geometrical coefficient of safety of $3 \cdot 6$.

The conclusion is clear: the problem is not simply the overturning of the buttress (as in retaining walls or dams). The design should be 'generous' in order to provide for unavoidable settlements and leanings. This means higher coefficients of safety and a greater depth/span ratio. The reader may check without difficulty how a buttress with a depth of $1 / 3$ of the span ( $2 \cdot 3 \mathrm{~m}$ instead of $1.6 \mathrm{~m}$, the Renaissance rule) would have withstood the actual leaning and consequent increase of the vault thrust. Indeed, most probably, the inclinations would have been much less and the problem then nonexistent. Only the final empirical experiment - the building itself - gives a correct indication as to the 'true' value for the geometrical coefficient of safety. In the author's experience, values of 4 or 5 (or even much higher) are not infrequent in well-preserved historical buildings.

\subsection{Compound buttresses}

The matter of the compound buttress - a wall reinforced with counterforts - is much more complex. The actual construction of the structure is of such importance as to make meaningless any calculations that do not take it into consideration. The thick walls usually have outer skins of more or less regular masonry and an inner core of rubble masonry. The method of bonding with the counterforts may vary significantly (Figure 23) and the nature of the rubble masonry may also vary with height - at Guimarei Church (Figure 4) the masonry of the core was very good at the springings of the vaults but very poor ('earth mortar') at the foot between the counterforts.

The behaviour of a compound buttress can be explained with reference to the several methods developed to calculate the 


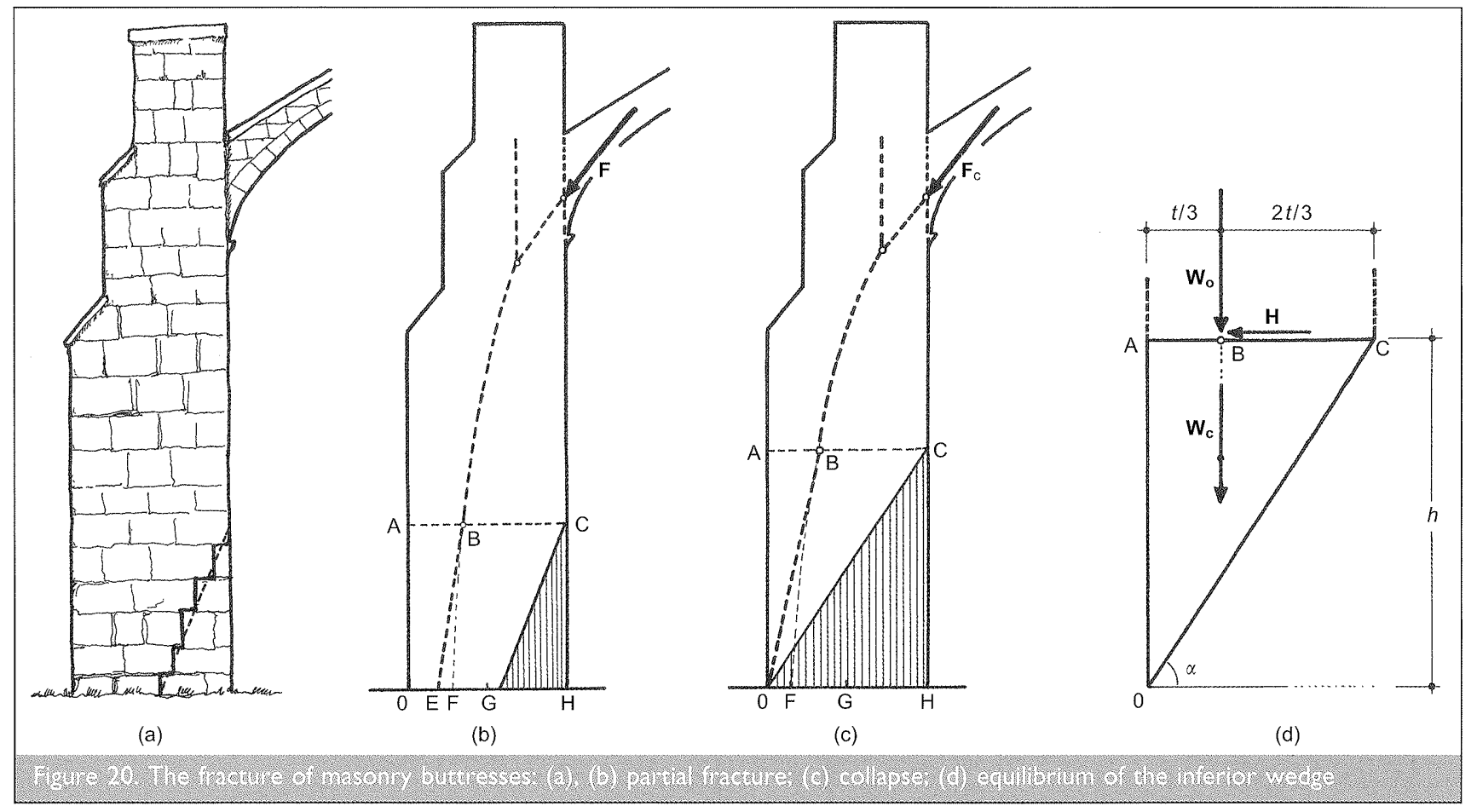

(Ochsendorf et al., 2004) giving a value around 30\% less than the collapse load for the monolithic buttress.

With regard to the safety of actual buttresses, the possibility of fracture establishes a minimum value for the geometrical coefficient of safety: to prevent formation of a fracture, the thrust should fall within the core. This is a geometrical condition. For buttresses of rectangular section, it is the "middle third' $\left(c_{\mathrm{g}}=3\right)$. For columns or nave piers of circular or nearly circular section, it is the 'middle fourth' $\left(c_{\mathrm{g}}=4\right)$. If the pier has nearly the section of a square rotated by $45^{\circ}$ and the overturning moment acts along the diagonal of the square, it is the 'middle sixth' $\left(c_{\mathrm{g}}=6\right)$ ). (This much more restrictive value for nave piers may help explain the gross deformations often observed in the transverse sections of Romanesque and Gothic churches.)

At first sight it would appear that Rankine's condition is correct for the design of building buttresses since it avoids the formation of any fracture. However, this is not the case, as will be shown later.

\subsection{The effect of leaning}

The buttresses of historical architecture are seldom perfectly vertical. A leaning of $0.5-1^{\circ}$ is very common; the walls of the church of Guimarei (Figure 4(b)) have had an inclination of around $1.5^{\circ}$ for the last three centuries. The effect of leaning on the moment of stability of a slender buttress may be important. Consider a prismatic buttress (of rectangular section) of depth $t$, breadth $1 \mathrm{~m}$ and height $h=\lambda t$. The moment of stability will be proportional to $h t(t / 6)$. An inclination of $\alpha$ would make this moment proportional to $h t[t / 6-\alpha(h / 2)]$. Therefore, the leaning will reduce the moment of stability by a factor $(1-3 \lambda \alpha)$. For $\alpha=$ $0 \cdot 5^{\circ}$, this means a reduction of $15 \%$; for $\alpha=1^{\circ}$, a reduction of $30 \%$.

The leaning has another effect on buttresses that support masonry vaults. The vault will suffer, as a consequence of a symmetrical leaning of $\alpha$ by both buttresses, an opening at the level of the imposts (vault springings) of the order of $2(h \alpha)$. Taking a height of $15 \mathrm{~m}$, that implies, for $\alpha=0.5^{\circ}$, an increase in the span of around $250 \mathrm{~mm}$. For $\alpha=1^{\circ}$, the span will increase by around $500 \mathrm{~mm}$. The increase of the span of the vault in Figure $4(\mathrm{~b})$ is $250 \mathrm{~mm}$ at the height of the imposts, $4.8 \mathrm{~m}$; for a span of $6 \mathrm{~m}$, this means an increase of $1 / 24$ of the span. The vault cracked at three points and this allowed its accommodation to this enormous increase of span; the original semicircular barrel vault turned into a surbaissée, quasi-oval, vault which is obviously in danger of collapsing by 'snap-through' with a little additional increase in leaning. It has been calculated that a leaning of $2 \cdot 1^{\circ}$, an increase of $40 \%$, would trigger the collapse of the vault (Huerta and López-Manzanares, 1997).

The distortion of the vault has another effect of paramount importance for the stability of the buttress: the thrust is roughly proportional to the degree of surbaissement and, in the case of Guimarei, this has increased the horizontal thrust by a factor of $1 \cdot 6$.

As a second case study, consider a theoretical case in which the buttress is a continuous wall supporting a semicircular barrel vault (Figure 21). The vault has a span $s=7 \mathrm{~m}$ and a thickness of $s / 20$; the buttress has been designed with a depth $t=1.6 \mathrm{~m}$. A first analysis, considering the buttress as monolithic, gives a geometrical coefficient of safety of $c_{\mathrm{g}}=3.6$ at the base. There is no danger of fracture and, apparently, the buttress is safe enough. However, this dimension gives a depth/span ratio of $1 / 4 \cdot 3$, which is much less than the $1 / 3$ recommended by the Renaissance empirical design rule and, also, by Fray Lorenzo (see Table 1). (The dimensions correspond roughly to the chapel of the Pazo de Antequeira, Rois, Galicia, built in the eighteenth century; the vault collapsed in the 1980s and expertise to rebuild the vault was required (Huerta et al., 1997).)

Let us explore the consequence of a leaning of $1^{\circ}$ (in the Rois chapel the inclinations were between 0.5 and $1.4^{\circ}$ ). Since the buttress has a nonuniform profile, let us consider, as above, a 


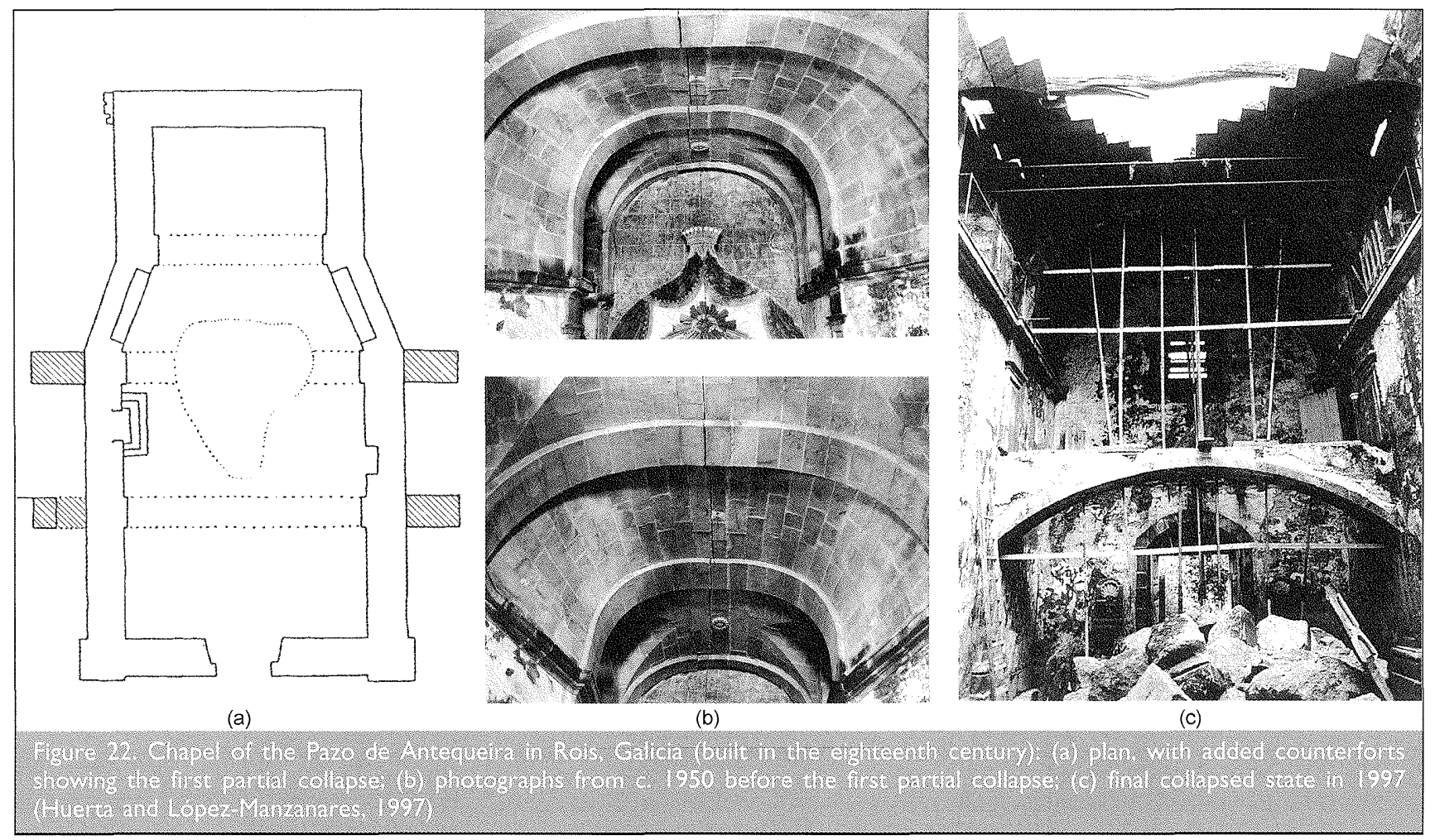

moment of stability of a buttress formed by a wall with counterforts. Figure 24 shows three modes of collapse (Huerta and López-Manzanares, 1996):

(a) the monolithic assumption where the whole system rotates around the boundary of the counterfort;

(b) the Audoy/Rankine assumption that considers, maybe too conservatively, that there is no connection between the buttresses (wall plus counterfort) and the wall between them; and

(c) a counterfort simply added to an existing wall.

If we take the moment of stability of case (a) as $M_{\mathrm{a}}=1$, then $M_{\mathrm{b}}$ $=0.5$ and $M_{\mathrm{c}}=0.3$. An intermediate case between (a) and (b), where a part of the wall is bonded to the buttress, is also possible; for example, if the length of wall attached at each side

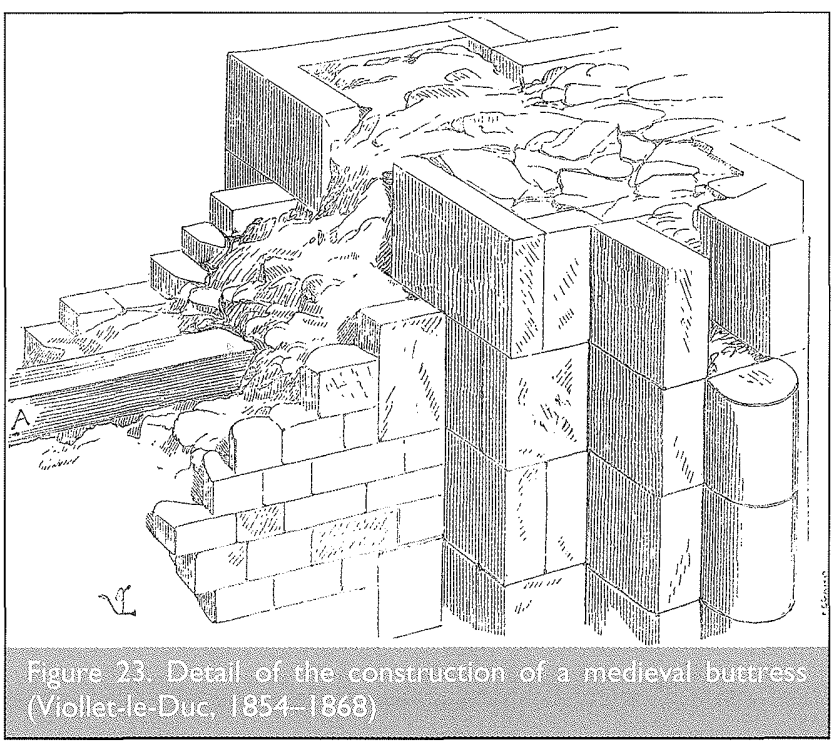

of the buttress is assumed to be half the thickness of the wall, then $M_{\mathrm{d}}=0 \cdot 6$.

It may also be the case that an upper part of the wall contributes to the stability through existing arches over the windows or the formation of 'relieving arches' inside the masonry (see Figure 25). All this, again, depends on the quality and state of the masonry, the movements that the structure has suffered, the nature of possible internal cracks, etc. A better understanding can only be found in the empirical rules and in the critical study of existing buildings. The assumption that part of the wall is well bonded to the buttress, so that it may collaborate in the stability, appears rational. The key question is the length of well-bonded wall that should be assumed.

Fray Lorenzo de San Nicolás gave detailed rules (Table 1) that were used by many Spanish architects in the design and building of parish churches until well into the nineteenth century and these churches now constitute a large body of experimental data and a resource for detailed study. The author studied the case of a stone barrel vault with a thickness 1/20th of the span and made calculations for its geometry as specified by Fray Lorenzo (Figure 26(a) and (b)). (The actual vaults of this time had lunettes, but they were small and did not affect the calculations.) The masonry of the walls, buttress and vaults is assumed to have uniform specific weight. The total length of wall bonded to the buttress is given by $\alpha t_{1}$. The calculations were made assuming a geometrical coefficient of safety $c_{\mathrm{g}}$ of 4 . It may be seen from the curves in Figure 26(c) that a ratio of depth of buttress to span of $1 / 3$ or higher corresponds to values of $\alpha$ between 0.5 and 1 , which sounds very reasonable. A better bonding would increase the value of $c_{\mathrm{g}}$ correspondingly.

\section{CONCLUSIONS}

In the middle of the nineteenth century Viollet-le-Duc wrote (Viollet-le-Duc, 1854-1868): 

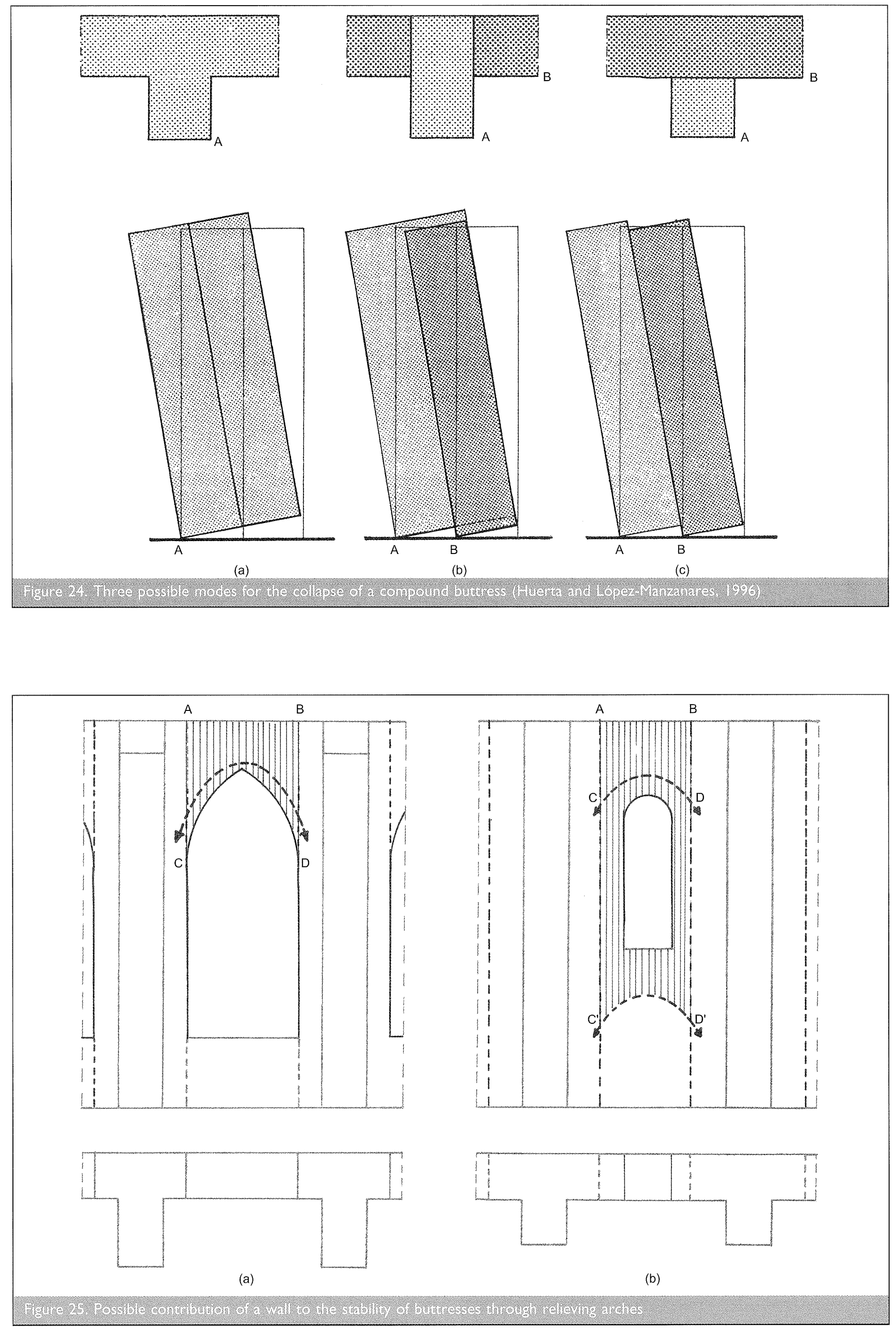


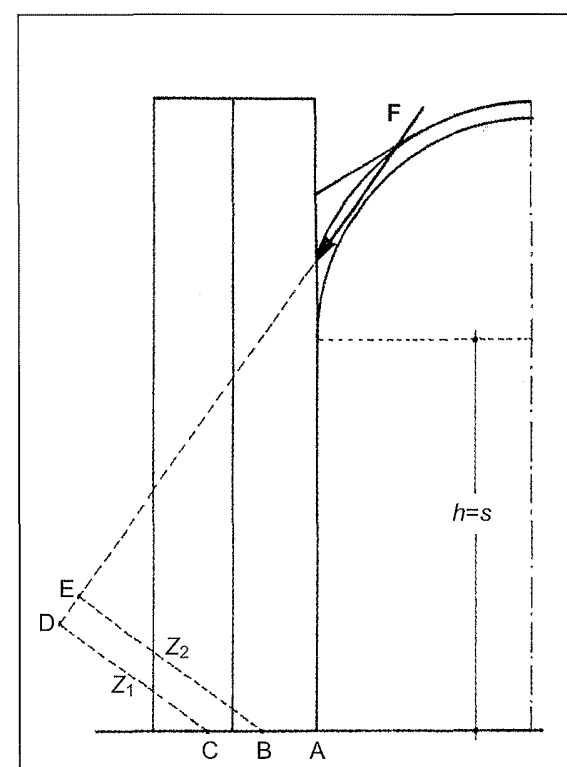

(a)

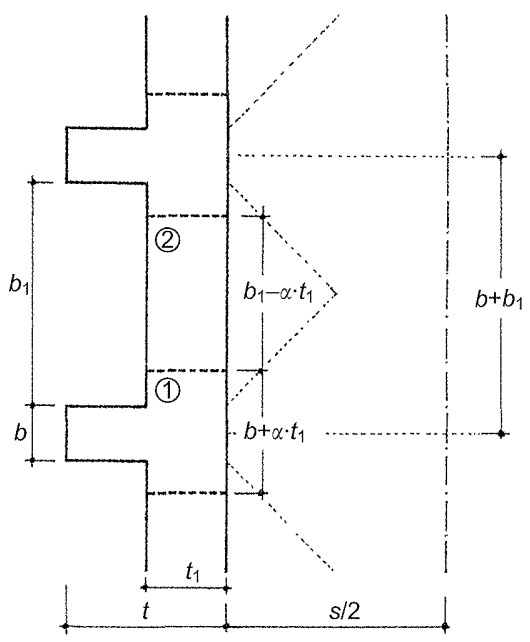

(b)

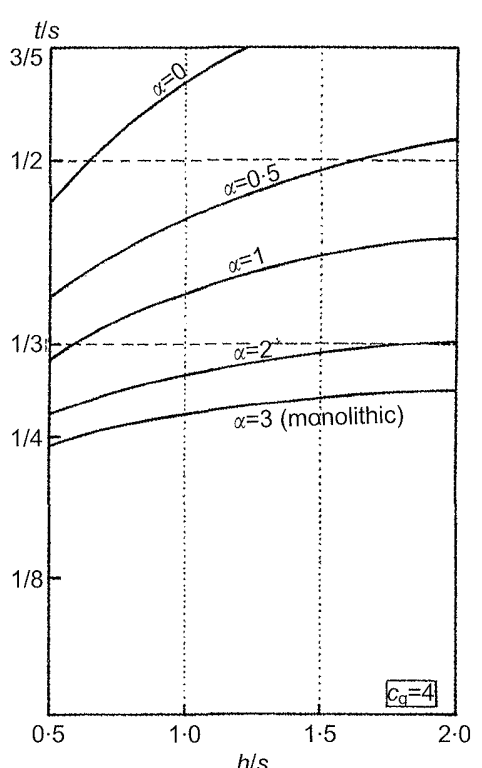

(c)

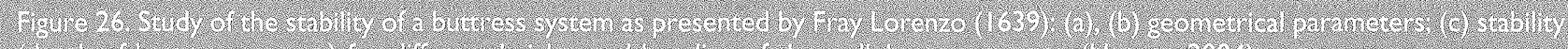

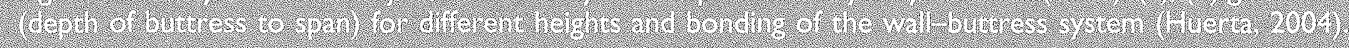

Le squelette cède ou résiste ... suivant le besoin et la place ... il semble posseder une vie, car il obéit à des forces contraires et son inmobilité n'est obtenu qu'au moyen de l'équilibre de ces forces

translated as

The skeleton yields or resists ... following the needs and the place ... it seems to be alive, because it obeys opposed forces and the stability is only acquired through the equilibrium of those forces.

The stability and safety of masonry architecture is a matter of geometry. The traditional geometrical design rules are of the correct form and represent the distillation of centuries of experience which have proved to be, even today, a reliable indication of actual factors of safety. A modern LSA of masonry leads to the same geometrical conclusions. Furthermore, LSA liberates designers from the 'elastic straightjacket' and permits them to concentrate on the crucial aspects of statical equilibrium.

The analyst's task is not to find the actual equilibrium state of a masonry structure - which is an impossible task - but to find, among the infinitely many equilibrium solutions, one that would permit them to answer the question or questions posed by the problem at hand. The study of a buttress should be considered in relation to the vault system it abuts. Again, the analyst should evaluate the situation and apply the corresponding simplifying assumptions.

The first requisite of a masonry buttress is to withstand the thrust of arches or vaults and wind loads. However, the buttress should also be so designed as to avoid significant deformations in the vaults. Due to the height of most masonry buttresses this imposes a severe restriction on the position of the line of thrust at the base, with the result that geometrical coefficients of safety for buttresses are much higher than those for arches (usually around 2).

The usual geometrical coefficient of safety of 3 (the "middle third rule', which avoids any tensile stresses in the buttress) appears to be insufficient to ensure the stability of structures over many centuries, as has been proven with much historical architecture. To arrive at this conclusion it has been necessary to combine historical research into how buildings were designed with the theoretical advances of modern LSA. This may be the most important conclusion: a historic masonry structure cannot be properly understood without a historical background of the building. Such buildings represent an invaluable 'experiment in progress' and should be regarded with respect and admiration.

\section{REFERENCES}

Audoy M (1820) Mémoire sur la poussée des voûtes en berceau. Mémorial de l'Officier du Génie 4: 1-96, plates 1-6.

Bélidor BF (1729) La Science des Ingénieurs dans la Conduite des Travaux de Fortification et Architecture Civile. Claude Jombert, Paris.

Benouville L (1891) Étude sur la cathédrale de Beauvais. Encyclopédie d'Architecture 4: 52, 60-62, 68-70, plates 159-161.

Cassinello F (1964) Bóvedas y Cúpulas de Ladrillo, 2nd edn. Insituto Eduardo Torroja de la Construcción y del Cemento, Madrid.

Choisy A (1899) Histoire de l'Architecture. Béranger, Paris. Derand F (1643) L'architecture des Voûtes ou l'art des Traits et Coupe des Voûtes. Sebastian Cramoisy, Paris.

García Berruguilla J (1747) Verdadera Práctica de las Resoluciones de la Geometría. Francisco Lorenzo Mojados, Madrid.

Heyman J (1966) The stone skeleton. International Journal of Solids and Structures 2: 249-279.

Heyman J (1967-1968) Beauvais Cathedral. Transactions of the Newcomen Society 40: 15-35.

Heyman J (1969) The safety of masonry arches. International Journal of Mechanical Sciences 11(4): 363-385.

Heyman J (1972) Coulomb's Memoir on Statics: An Essay in the History of Civil Engineering. Cambridge University Press, Cambridge. 
Heyman J (1982) The Masonry Arch. Ellis Horwood, Chichester. Heyman J (1992) Leaning towers. Meccanica 27(3): 153-159.

Heyman J (1995) The Stone Skeleton. Structural Engineering of Masonry Architecture. Cambridge University Press, Cambridge.

Heyman J (1998a) Hooke's cubico-parabolical conoid. Notes and Records of the Royal Society of London 52(1): 39-50.

Heyman J (1998b) Structural Analysis: A Historical Approach. Cambridge University Press, Cambridge.

Heyman J (2001) Personal communication, March 13.

Heyman J (2003) Wren, Hooke and Partners. Proceedings of the First International Congress on Construction History (Huerta S. (ed.)). Instituto Juan de Herrera, Madrid, pp. 3-9.

Heyman J (2005) Theoretical analysis and real-world design. Structural Engineer 83(8): 14-17.

Heyman J (2008) Basic Structural Theory. Cambridge University Press, Cambridge.

Hooke R (1676) A Description of Helioscopes and Some Other Instruments Made by Robert Hooke. J. Martyn, London.

Huerta S (2004) Arcos, Bóvedas y Cúpulas. Geometria y Equilibrio en el Cálculo Tradicional de Estructuras de Fábrica. Instituto Juan de Herrera, Madrid See www.ad.upm.es for further details (accessed 18/08/2009).

Huerta S (2005) Thomas Young's theory of the arch: his analysis of Telford's design for an iron arch of 600 feet span. Essays in the History of the Theory of Structures, in Honour of Jacques Heyman (Huerta S (ed.)). Instituto Juan de Herrera, Madrid, pp. 189-233.

Huerta S (2006) Structural design in the work of Gaudí. Architectural Science Review 49(4): 324-339.

Huerta S (2008) The analysis of masonry architecture: a historical approach. Architectural Science Review 51(4): 297-328.

Huerta S and Foce F (2003) Vault theory in Spain between XVIIIth and XIXth century: Monasterio's unpublished manuscript Nueva Teórica de las Bóvedas. Proceedings of the First International Congress on Construction History (Huerta S (ed.)). Instituto Juan de Herrera, Madrid, 2, pp. 1155-1166.

Huerta S and López-Manzanares G (1996) Informe Sobre la Estabilidad de la Iglesia de Guimarei. Polytechnic University of Madrid, Technical report. See www.ad.upm.es for further details (accessed 18/08/2009).

Huerta S and López-Manzanares G (1997) Stability and consolidation of an ashlar barrel vault with great deformations: the church of Guimarei. Structural Studies, Repairs and Maintenance of Historical Buildings (Sánchez-Beitia S and Brebbia CA (eds)). Computational Mechanics Publications, Southampton, pp. 587-596.

Huerta S, Rabasa E and López-Manzanares G (1997) Estudios Estructurales Previos a la Restauración de la Capilla del Pazo de Antequeira en Rois. Polytechnic University of Madrid, Technical report. See www.ad.upm.es for further details (accessed 18/08/2009).

Hutton C (1812) Tracts on Mathematical and Philosophical Subjects Comprising, among numerous important articles, The Theory of Bridges. Wilkie and Robinson, London.

La Hire P (1712) Sur la construction des voûtes dans les édifices. Mémoires de l'Académie Royale des Sciences de Paris: 69-77.

Martínez de Aranda G. (c. 1590) Cerramientos y Trazas de Montea. Ms. Biblioteca de Ingenieros del Ejército, Madrid.

Monasterio SA (c. 1800) Nueva teorica sobre el empuje de Bovedas. Ms. Biblioteca de la Escuela Técnica Superior de Ingenieros de Caminos, Canales y Puertos, Caja $2 \alpha 508$.

Moseley H (1843) Mechanical Principles of Engineering and Architecture. Longman, Brown, Green and Longmans, London.

Müller W (1990) Grundlagen Gotischer Bautechnik. Deutscher Kunstverlag, München.

Ochsendorf J and De Lorenzis L (2008) Failure of rectangular masonry buttresses under concentrated loading. Proceedings of the Institution of Civil Engineers, Structures and Buildings 161(5): 265-276.

Ochsendorf JA (2002) Collapse of Masonry Structures. PhD dissertation, University of Cambridge, UK.

Ochsendorf JA, Hernando JI and Huerta S (2003) Análisis a rotura de estribos de fábrica. Revista de Obras Públicas 150: 27-42 See www.ad.upm.es for further details (accessed 18/08/2009).

Ochsendorf JA, Hernando JI and Huerta S (2004) Collapse of masonry buttresses. ASCE Journal of Architectural Engineering 10(3): 88-97.

Rankine WJM (1858) A Manual of Applied Mechanics. Charles Griffin, London.

San Nicolás FL (1639) Arte y Uso de Architectura. Primera parte. Madrid.

Ungewitter GG and Mohrmann K (1890) Lehrbuch der Gotischen Konstruktionen, 3rd edn. Weigel Nachfolger, Leipzig.

Viollet-le-Duc E (1854-1868) Dictionnaire Raisonnée de l'Architecture Française du XI au XVI Siécle. Morel, Paris.

\section{What do you think?}

To discuss this paper, please email up to 500 words to the editor at journals@ice.org.uk. Your contribution will be forwarded to the author(s) for a reply and, if considered appropriate by the editorial panel, will be published as discussion in a future issue of the journal.

Proceedings journals rely entirely on contributions sent in by civil engineering professionals, academics and students. Papers should be 2000-5000 words long (briefing papers should be 1000-2000 words long), with adequate illustrations and references. You can submit your paper online via www.icevirtuallibrary.com/content/journals, where you will also find detailed author guidelines. 